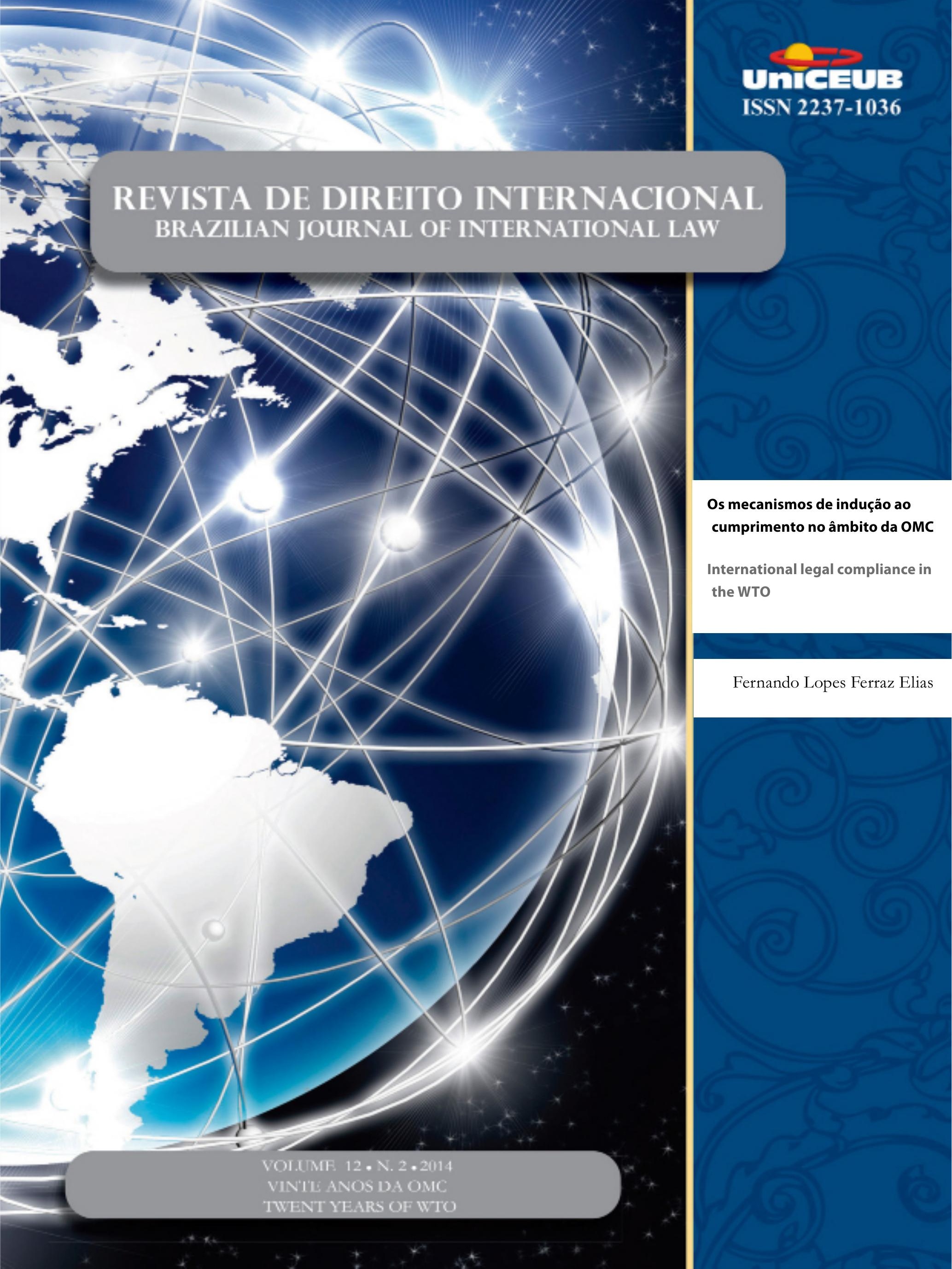


I. Crônicas

1. Crônicas da atualidade do Direito Internacional ......................................................16

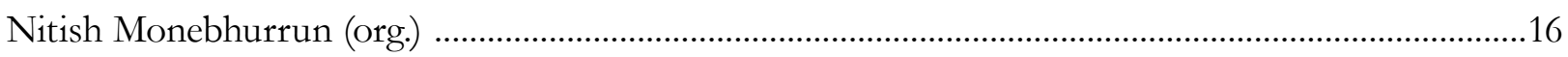

2.Decisões da Corte Internacional de Justiça e do Tribunal Internacional Sobre o Direito do Mar

Nitish Monebhurrun

José Eduardo Siqueira

3. Crônicas do direito internacional dos inVestimentos

Nitish Monebhurrun

\section{Os Vinte Anos dA OMC}

EXPORT CONTROLS AS INDUSTRIAL POLICY ON NATURAL RESOURCES: REGULATORY LIMITATIONS ON CHINA - RAW MATERIALS AND CHINA - RARE EARTHS CASES.

Gustavo Ferreira Ribeiro

O problema da espionagem econômica internacional: Seria a Organização Mundial do CoMÉRCIO O FORO ADEQUADO PARA SUA APRECIAÇÃO?

Humberto A.Vasconcelos Lima

Naiana Magrini Rodrigues Cunha

International Standards for Intellectual Property Rights Protection: a reflection on CLIMATE-FRIENDLY TECHNOLOGY TRANSFER.

Guihong Zhang

Jiani Jiang

Can Wang

Os vinte anos da OMC, suas conquistas e desafios: uma análise do Brasil e o Sistema de SoLUÇõES DE CONTROvÉRsias

Etiene M. Bosco Breviglieri

Luciano Meneguetti Pereira

A relação entre os tratados multilaterais ambientais e os acordos da OMC: é possível CONCILIAR O CONFLITO?

Fabio Costa Morosini,

Luisa Zuardi Niencheski 
Um desafio na Organização Mundial do Comércio: Viabilidade de um aCordo plurilateral SOBRE ENERGIA

Matheus Linck Bassani

CONTRATAÇÕES PÚBLICAS NO ÂMBITO DA OMC: A POLÍTICA LEGISLATIVA BRASILEIRA À LUZ DO DIREITO AO DESENVOLVIMENTO 192

André Jansen do Nascimento

Governança global e a Organização Mundial do Comércio: desafios impostos pelo novo MANDATO DE DESENVOLVIMENTO

Letícia de Souza Daibert

Ana Luísa Soares Peres

Vinte Anos de Crise para a África? Poder, Assimetrias e a Abordagem liberal da OMC.....239 Igor Abdalla Medina de Souza

Os MECANISMOS DE INDUÇÃo AO CUMPRIMENTO NO ÂMBITO DA OMC .258

Fernando Lopes Ferraz Elias

A promoção de accountability na Organização Mundial do ComérCio: uma análise horiZONTAL E VERTICAL

Celso Henrique Cadete de Figueiredo

LA OMC y EL PROCESO DE GLOBALIZACION DE LA REGULACIÓN ALIMENTARIA

Maria Eugenia Marichal

O ACORDo GATS E SUA APLICAÇão AOS SERVIÇOS DO COMÉRCIO ELETRÔNICO

Gleisse Ribeiro Alves

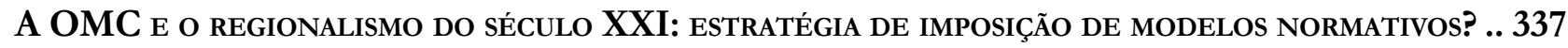
Camilla Capucio

A organizaÇão mundial do Comércio e a China: direito de Propriedade E PRopriedade INTELECTUAL NO PAÍS 349

Dos contenciosos na OMC com ENFoque EM REstrições Às EXPortações da China .363

Marco Antônio Alcântara Nascimento 
O Redimensionamento da OMC no trato dos Acordos Comerciais Regionais........................387

Alice Rocha da Silva

\section{Outros Temas}

Derechos Humanos EN LA REALIDAd ACTUAL: LA GLOBALIZACión Y EL MULTICULTURALisMo

David Falcão

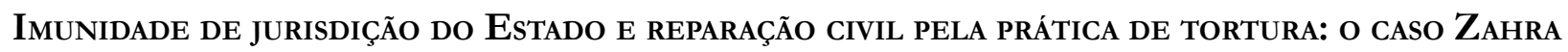

KAZEMI v. RepÚbliCA IsLÂMICA do IrÃ

Patrícia Maria Lara Abreu

Rodrigo Otávio Bastos Silva Raposo

INTERREgIONAL ORgANIZATIONS (IROS) IN EUROPE: NEW SUBJECTS OF CONTEMPORARY INTERNATIONAL LAW?

Davorin Lapas

A Conexão entre os direitos humanos e a Corrupção.

Gabriela Alves Mendes Vieira

Marcelo Dias Varella

GRUPO DE SOCIEDADES: INSTRUMENTO JURÍDICO DE ORGANIZAÇÃo DA EMPRESA PLURISSOCIETÁRIA......495

Daniel Amin Ferraz 


\title{
Os mecanismos de indução ao cumprimento no âmbito da OMC*
}

\author{
International legal compliance in the WTO
}

\author{
Fernando Lopes Ferraz Elias**
}

\section{Resumo}

O presente artigo visa investigar os mecanismos de indução ao cumprimento no âmbito da OMC. Primeiramente, contextualizamos, política e juridicamente, a questão da implementação das regras e decisões da OMC. Em seguida, examinamos os fatores que influenciam o descumprimento das regras e das decisões da OMC pelos países desenvolvidos, em desenvolvimento e de menor desenvolvimento relativo. Adiante, destacamos as formas de descumprimento das regras e das decisões da OMC e analisamos dados e estatísticas do sistema. Por fim, propomos mudanças para o aprimoramento do cumprimento das decisões da OMC. Concluímos que a questão da conformidade é central para o funcionamento das instituições internacionais, com a OMC na vanguarda. A eficácia do regime jurídico da OMC depende da sua capacidade de indução ao cumprimento das decisões dos painéis e do órgão de apelação. Hoje, a solução de litígios comerciais internacionais é tanto o resultado de ingerências políticas quanto de um verdadeiro interesse em aprimorar as condições do comércio internacional. Destarte, é fundamental perscrutarmos em que extensão os atuais níveis de descumprimento das obrigações comerciais podem constituir uma ameaça a um regime jurídico relativamente bem organizado, e até agora, em parte, efetivo; ou, ao contrário, são necessários para a sua operação contínua em um sistema de comércio multilateral marcado por acentuadas assimetrias de poder. Portanto, o presente estudo é dotado de originalidade e, despido de pretensões de exaurir o tema, utiliza fontes de documentação direta e indireta nacional, internacional e estrangeira, a exemplo de leis, jurisprudências, livros e artigos científicos.

Palavras-chave: Mecanismos de indução ao cumprimento. Acordo Geral de Tarifas e Comércio (GATT). Organização Mundial do Comércio (OMC). Países desenvolvidos, em desenvolvimento e de menor desenvolvimento relativo.

\section{Abstract}

The aim of this paper is to investigate the international legal compliance in the WTO. First, we contextualize, politically and legally, the issue of WTO rules and decisions' implementation. Next, we examine the factors that influence noncompliance with the rules and decisions of the WTO by developed countries, developing countries and less developed countries. Forward, we highlight the forms of noncompliance with the rules and decisions of the WTO and we analyze data and statistics of the system. Finally, we propose changes to improve compliance with WTO rulings. We conclude that the issue of compliance is central to the functioning of international institutions, the WTO at the forefront. The effectiveness of the legal framework of the WTO depends on its ability to

\footnotetext{
* Recebido em 30.10.2014

Aceito em 27.11.2014

** Bacharel em Direito e Relações Internacionais pela PUC-SP, Mestre em Relações Internacionais pela UNISUL, Doutorando em Direito pelo UNICEUB, flfe@ig.com.br.
} 
induce compliance with the decisions of panels and the appellate body. Today, the settlement of international commercial disputes is the result of political interference and a genuine interest in improving the conditions of international trade. Thus, it is essential we scrutinize in what extent the current levels of noncompliance with trade obligations may constitute a threat to a relatively well-organized legal system, and so far, partly effective; or, conversely, are necessary for its continued operation in a multilateral trading system that is defined by sharp power asymmetries. Therefore, this study is endowed with originality and, without pretensions to exhaust the subject, uses sources of direct and indirect documentation national, international and foreign, like laws, jurisprudence, books and scientific articles.

Keywords: International legal compliance. General Agreement on Tariffs and Trade (GATT). World Trade Organization (WTO). Developed countries, developing countries and less developed countries.

\section{Introdução}

Uma das mais importantes questões recentemente suscitadas no âmbito da OMC é a do respeito às regras e decisões dos painéis e do órgão de apelação do sistema de solução de controvérsias. Uma vez que uma decisão foi proferida, como pode uma parte reclamante garantir que a parte reclamada irá fielmente implementá-la? Que recurso está disponível para o autor da denúncia, se o réu de uma disputa altamente politizada recusar-se a cumpri-la?

No direito internacional, de modo geral, é difícil tomar medidas coercitivas quando os estados não cooperam. Na OMC, especificamente, é diferente, em razão da estrutura do OSC, com destaque para a possibilidade de imposição de medidas retaliatórias ao membro que descumpre as regras e decisões da organização. Contudo, descontextualizado dos interesses dos atores políticos, esse expediente não tem sido suficiente para resolver as deficiências pertinentes ao cumprimento, uma vez que não é possível estabelecer uma relação direta entre a natureza coercitiva da norma comercial internacional e o comportamento dos estados. Não podemos olvidar que a OMC foi constituída como uma criatura híbrida, tanto jurídica quanto diplomática. Por isso, devemos questionar quem serve melhor aos objetivos econômicos do sistema de comércio internacional, se a lei ou a negociação.
A importância do poder político e econômico emoldura o contexto no qual se podem compreender os principais fatores que influenciam a conformidade às regras e às decisões da $\mathrm{OMC}$ por parte dos países desenvolvidos, em desenvolvimento e de menor desenvolvimento relativo, a ponto de se repensar a própria viabilidade do ESC como um mecanismo idôneo para a resolução de disputas comerciais internacionais, supedâneo de um sistema baseado no direito ao invés de um sistema baseado no poder. Por um lado, destaca-se a dificuldade do OSC de induzir o cumprimento das regras da OMC, bem como de suas decisões, aos países desenvolvidos diante de: (i) situações de ausência de pressão da comunidade internacional; (ii) aspectos estruturais do sistema de solução de controvérsias; (iii) receio de perda de soberania. Por outro, as decisões do painel e do órgão de apelação da OMC, em relação aos dos países em desenvolvimento e de menor desenvolvimento relativo, são incapazes de minimizar a desconformidade frente: (i) à influência dramática da força política e econômica dos países desenvolvidos sobre o processo de solução de controvérsias; (ii) ao descumprimento das decisões da OMC pelos países desenvolvidos; (iii) aos aspectos técnicos do sistema de solução de controvérsias da OMC; (iv) à impossibilidade dos países em desenvolvimento de utilizarem o mecanismo da retaliação; (v) à falta de capacidade técnica e de recursos financeiros aos países em desenvolvimento.

A não conformidade dos membros da OMC, geralmente, materializa-se das seguintes maneiras: (i) descumprimento prévio; (ii) descumprimento temporário; (iii) morosidade; e (iv) descumprimento, aberto e disfarçado. $\mathrm{Na}$ maioria dos casos, entretanto, a maioria dos membros - tanto os maiores como os menores — implementa a maior parte dos relatórios do painel e do órgão de apelação, principalmente, a fim de se assegurar a legitimidade de um sistema baseado em regras. Isso faz com que a taxa de cumprimento no âmbito da OMC seja muito boa. Contudo, vista mais de perto, se considerados os números dos casos de cumprimento não integral somados aos casos de morosidade persistente até o pleno cumprimento, isto é, qualidade e tempo de cumprimento, respectivamente, chega-se a um índice de descumprimento muito superior ao do antigo GATT, o que recomenda reformas na $\mathrm{OMC}$, desde que não sejam meramente legalistas e atendam aos interesses peculiares dos seus membros. 


\section{Entre a política e o direito, a implementação das regras e das decisões da OMC}

Não há dúvida de que o mais convincente fator para o cumprimento de uma diretriz ${ }^{1}$ relativa ao comércio internacional é que ela decorra de um processo legal. ${ }^{2} \mathrm{~A}$ judicialização das disputas comerciais e o trabalho consistente dos juízes têm potencializado a força normativa dos acordos e promovido um regime de comércio internacional baseado em regras. Essa visão é reforçada pela taxa de êxito dos demandantes entre 80 e 90 por cento das disputas, resultado de uma interpretação judicial dos textos da OMC a partir de uma visão liberal de livre comércio. ${ }^{3}$ Sistemas de regulação baseados em regras são preferidos pelos países porque: (i) apresentam mais e melhores recursos para a solução dos conflitos; (ii) são a maneira mais eficaz de negociar e capturar mudanças políticas desejadas em passos incrementais possíveis; (iii) criam as condições mais previsíveis para as decisões das empresas; (iv) ajudam a cimentar as próprias políticas liberais de comércio contra as pressões políticas internas protecionistas. ${ }^{4}$

Em última instância, as regras do comércio internacional são estabelecidas para aumentar o bem-estar nacional e mundial por meio do uso mais eficiente dos recursos. Parece pouco provável que uma abordagem mais orientada para o poder elevaria o bem-estar nacional ou mundial. A ameaça de guerras comerciais cresceria, particularmente, no caso de

1 É importante distinguir o cumprimento das obrigações primárias da OMC - a promoção do que é o objetivo final do ESC - do cumprimento das decisões e recomendações do OSC. Conquanto este seja certamente relevante para aquele e o influencie direta e indiretamente, ambos não são a mesma coisa. Decisões e recomendações do OSC são, necessariamente, produtos de controvérsias não resolvidas por meio de consultas e mediações. De fato, menos da metade desses casos são submetidos ao OSC. Portanto, são, naturalmente, os casos mais difíceis, do ponto de vista jurídico ou político. VAZQUEZ, Carlos M.; IACKSON, John H. Some reflections on compliance with WTO dispute settlement decisions. Law and Policy in International Business, v. 33, n. 4, p. 555-568. 2002.

2 BRIMEYER, Benjamin L. Bananas, beef, and compliance in the world trade organization: the inability of the WTO dispute settlement process to achieve compliance from superpower nations. Minnesota Journal of Global Trade, v. 10, p. 166, 2001.

3 COLARES, Juscelino F. Thelimits of WTO adjudication: is compliance the problem? Journal of International Economic Law, v. 14, n. 2, p. 403-436, 2011.

4 HUDEC, Robert E. The new WTO dispute settlement procedure: an overview of the first three years. Minnesota Journal of Global Trade, v. 8, n. 1, p. 10, 1999. disputas entre países poderosos. Além disso, reduziria a previsibilidade e a estabilidade do sistema, exigências das empresas privadas, prejudicando a alocação de recursos por parte delas. E, ainda, o poder poderia ser exercido para interesses particulares e fins protecionistas. Portanto, os interesses dos consumidores, bem como o bem-estar dos cidadãos, aumentariam mesmo na hipótese em que o país deles viesse a ser derrotado em um litígio no âmbito da OMC.

Uma análise dos mecanismos de solução de controvérsias mostra que, embora a OMC estabeleça um regime mais orientado para o direito, ainda lhe falta o poder de impor o cumprimento das suas decisões. ${ }^{6} \mathrm{~A}$ politização das disputas torna o Entendimento sobre Solução de Controvérsias (ESC) inoperante para a implementação dos seus direitos. A inexistência de um cumprimento coercitivo envenena a relação entre os países. Ir ao OSC não se traduz no automático cumprimento de suas decisões, sendo este o verdadeiro desafio para a $\mathrm{OMC}^{\top} \mathrm{A}$ aplicação efetiva das decisões do OSC é essencial para garantir a integridade contínua do sistema de solução de controvérsias da OMC. No entanto, é evidente que a tão anunciada "automaticidade" tem suas limitações. A aceitação automática dos relatórios do painel e do órgão de apelação, bem como dos pedidos de retaliação, não é garantia de cumprimento automático.

Em contraponto, não há uma relação direta entre o caráter obrigatório de determinada norma e o incentivo a certa conduta, sem considerar o contexto em que ambos estão insertos. Portanto, devemos analisar quais mecanismos produzem um maior respeito às normas e em quais circunstâncias o cumprimento das normas é algo verdadeiramente útil. A lei é imprecisa e

5 SCHAEFER, Matthew. National review of WTO dispute settlement reports: in the name of sovereignty or enhanced WTO rule compliance? St. John's Journal of Legal Commentary, v. 11, n. 2, p. 335-336, 1996.

6 KHANSARI, Azar M. Searching for the perfect solution: international dispute resolution and the new world trade organization. Hastings International and Comparative Law Review, v. 20, n. 1, p. 189, 1996.

7 IERLEY, Douglas. Defining the factors that influence developing country compliance with and participation in the WTO dispute settlement system: another look at the dispute over bananas. Law and Policy in International Business, v. 33, p. $627,2002$.

8 MCGIVERN, Brendan P. Seeking compliance with WTO rulings: theory, practice and alternatives. International Lanyer $(A B A)$, v. 36, n. 1, p. 157, 2002. 
imperfeita, como nossa sociedade e nós mesmos. Não devemos imaginar que a condição natural da lei seja o seu cumprimento, ao contrário, sistemas jurídicos devem ser avaliados por sua maturidade, ou seja, se oferecem uma ampla variedade de opções sociais que permitem decisões políticas flexíveis em situações específicas.

No âmbito europeu, essa discussão do cumprimento do direito da OMC pode dar razão para o otimismo ou o pessimismo por parte daqueles que desejam melhores padrões de conformidade. Por um lado, os otimistas podem argumentar que a legislação da OMC impactou a forma como a Comunidade Europeia (CE) lida com o processo de restrição do comércio. De modo geral, a criação da OMC reforça o cumprimento da lei do comércio internacional. Por outro lado, os resultados podem encorajar o pessimismo entre aqueles desejosos de que a conformidade não dependa das conveniências políticas dos estados membros, mas sim de mecanismos coercitivos. É duvidoso que os acordos internacionais possam alcançar este tipo de cumprimento institucionalmente garantido. No final, o cumprimento será sempre o resultado de um cálculo político além das regras da OMC ou da possibilidade de retaliação. O cumprimento é estimulado ou desestimulado de acordo com os interesses dos atores políticos domésticos. Ao mesmo tempo, isso não reduz a questão da conformidade a uma questão de conveniência política doméstica, um bem desenhado projeto das instituições internacionais pode de fato aumentar a probabilidade de cumprimento, como o fez a OMC. O fortalecimento de um sistema de resolução de litígios pode contribuir para tornar mais difícil o descumprimento, ou seja, as instituições internacionais podem estruturar processos políticos que conduzam ao cumprimento de tal modo que a conformidade torna-se mais ou menos provável. É na interação entre direito e política que a conformidade é finalmente promovida. ${ }^{10}$

$\mathrm{O}$ efeito direto das decisões quer dizer que os Judiciários dos estados membros podem dar efeito imediato a uma medida tomada no âmbito da OMC. Entretanto, de acordo com a relação entre o direito nacional e o direito internacional em cada país, essa

9 TRACHTMAN, Joel P. Bananas, direct effect and compliance. European Journal of International Law, v. 10, n. 4, p. 656-657, 677, 1999.

10 PRINCEN, Sebastiaan. EC compliance with WTO law: the interplay of law and politics. European Journal of International Law, v. 15, n. 3, p. 555-574, 2004. mudança seria tão atraente para estados que optam pela prevalência dos tratados sobre as leis internas, mesmo posteriores aos compromissos firmados internacionalmente, quanto poderia significar a ineficácia do sistema nos estados em que esta relação não é tão clara, como no Brasil, uma vez que a vigência do tratado poderia ser considerada suspensa (ou mesmo revogada) à luz da norma interna posterior. Assim, a efetividade das decisões ficaria refém do grau de monismo ou dualismo de cada estado membro e o sistema todo contaminado pela insegurança jurídica e pela falta de agilidade dos Judiciários nacionais, cujos processos internos são, na maioria das vezes, muito mais morosos do que no âmbito multilateral, a exemplo do contencioso Comunidades Europeias - Pneus, cuja medida se tornou ineficaz pela própria morosidade do Judiciário brasileiro em proferir em tempo razoável uma decisão definitiva. ${ }^{11}$

A mais importante questão quanto à implementação é determinar se o efeito direto é adequado ao nível e ao tipo da força normativa obrigatória desejada. O efeito direto deve ser concebido em termos de preferência e não como uma teoria abstrata descontextualizada das instituições políticas. Essa é uma avaliação e um envolvimento que cabe aos atores políticos, consoante os interesses públicos. Certamente os EUA teriam rejeitado a Rodada Uruguai se as normas da OMC exigissem a produção de efeitos diretos. Trata-se de uma questão política que deve ser respondida em termos políticos. A falta de efeito direto deve ser vista como um mecanismo que reforça a legitimidade democrática dos estados, conquanto favoreça os mais poderosos e reduza o cumprimento das normas. Portanto, não há problemas no ESC, senão a necessidade de direito e política coexistirem. O nirvana do cumprimento perfeito é uma quimera. ${ }^{12}$

Se os membros tivessem desejado um cumprimento perfeito, poderiam ter fornecido sanções duras pelo descumprimento e criado um equivalente internacional a uma força policial coercitiva. Os membros não o fizeram, nem há possibilidade de que o façam. Sem dúvida, isso reflete, em certa medida, o fato de que

11 VARELLA, M. D. Efetividade do Órgão de Solução de Controvérsias da Organização Mundial do Comércio: uma análise sobre os seus doze primeiros anos de existência e das propostas para seu aperfeiçoamento. Revista Brasileira de Politica Internacional, v. 52, n. 2, p. 19, 2009.

12 TRACHTMAN, Joel P. Bananas, directeffectandcompliance. European Journal of International Law, v. 10, n. 4, p. 676-678, 1999. 
os membros não desejavam o cumprimento perfeito, pois não estavam dispostos a pagar o preço, em termos de soberania, por um regime que alcançaria esse grau de cumprimento. Contudo, isso não significa que eles queriam apenas o cumprimento daquilo com que concordam. ${ }^{13}$ No final, uma eventual alteração do ESC para produzir uma maior conformidade com as normas primárias é tanto uma questão política quanto técnica. Depende da vontade dos membros e eles podem preferir remédios menos invasivos. ${ }^{14}$

A estrutura jurídica da OMC fornece aos membros uma flexibilidade intra e extracontratual, tanto no âmbito dos limites da negociação quanto além dele, para garantir que, num primeiro momento, estados soberanos permaneçam dispostos a entregar grande parte da sua liberdade de ação em questões comerciais ao aderir à $\mathrm{OMC}$, e, num segundo momento, participem, no futuro, de rodadas de liberalização do comércio. Mais importante ainda, todas as iniciativas de atribuir ao processo de solução de controvérsias da OMC sanções mais duras, a fim de forçar os membros que se encontram em estado de violação à imediata conformidade, podem ser perfeitamente compatíveis com a natureza jurídica da solução de controvérsias bem como das obrigações internacionais. No entanto, elas ignoram completamente que o mecanismo de execução, aparentemente fraco, da OMC, por exemplo, permissivo ao descumprimento temporário das obrigações e decisões do órgão, serve como uma valiosa válvula de segurança sistêmica. Ademais, constata-se que esse expediente — baseado no regime de renegociação e alteração unilateral de tarifas e serviços, sob os artigos XXVIII do Acordo Geral de Tarifas e Comércio (GATT) de 1994 e XXI do Acordo Geral sobre Comércio de Serviços (GATS), que é parte explícita do acordo da OMC — tem sido utilizado pelos países membros apenas em circunstâncias verdadeiramente excepcionais. ${ }^{15}$

13 VAZQUEZ, Carlos M.; IACKSON, John H. Some reflections on compliance with WTO dispute settlement decisions. Law and Policy in International Business, v. 33, n. 4, p. 555568, 2002.

14 HUDEC, Robert E. Broadening the scope of remedies in WTO dispute settlement. In: WEISS, Friedl (Coord.). Improving WTO dispute settlement procedures: issues and lessons from the practice of other international courts and tribunals. London: Cameron May, 2000. p. 345-376.

15 ZIMMERMAN, Claus D. Toleration of temporary noncompliance: the systemic safety valve of WTO dispute settlement revisited. Trade, Law and Development, v. 3, n. 2, p. 382-406, 2011.
O aumento da coerção e de seu monitoramento tem como premissa o fortalecimento das obrigações normativas prescritas nos acordos comerciais. Essa visão ingenuamente pressupõe que os membros podem ser forçados a cumprir, mesmo quando o cumprimento é contrário aos seus próprios interesses. Finalmente, o cumprimento imperfeito não constitui nenhuma ameaça para o regime comercial. Ao invés disso, é essencial uma válvula de escape num sistema impulsionado pela crescente judicialização e ativismo jurídico. Vista dessa perspectiva mais flexível, a não conformidade aparece como um último recurso, acomodando os fortes interesses políticos e econômicos dos membros que já não podem contar com a flexibilidade diplomática do antigo GATT. Consequentemente, em vez de ameaçar a normatividade do sistema de comércio, tais desvios raros permitem a sua operação contínua enquanto as suas regras não podem constranger economias fortes, tampouco minimizar assimetrias de poder do sistema multilateral. ${ }^{16}$

Ademais, o adensamento de juridicidade poderia ser ruim para o crescimento do multilateralismo econômico, edificado sobre negociações mais políticas do que jurídicas. ${ }^{17} \mathrm{O}$ descumprimento persistente não implica sequer uma mudança permanente de direitos, uma vez que, de acordo com as regras do ESC, o direito da OMC é melhor analisado como sendo uma regra de propriedade e não uma regra de responsabilidade. Destarte, acomoda, de uma maneira muito equilibrada, flexibilidade extracontratual e segurança jurídica. Isso permite uma crescente liberalização do comércio mundial, beneficiando os membros e as pessoas físicas. ${ }^{18}$

Nesse sentido, os membros não são obrigados a cumprir as disposições dos acordos, caso lhes seja mais conveniente violá-los e sofrerem a suspensão das concessões nos termos do artigo 22 do ESC. Todavia, é difícil de entender como o ESC poderia promover a previsibilidade na $\mathrm{OMC}$ se a única responsabilidade

16 COLARES, Juscelino F. Thelimits of WTO adjudication: is compliance the problem? Journal of International Economic Law, v. 14, n. 2, p. 403-436, 2011.

17 VARELLA, M. D. Efetividade do Órgão de Solução de Controvérsias da Organização Mundial do Comércio: uma análise sobre os seus doze primeiros anos de existência e das propostas para seu aperfeiçoamento. Revista Brasileira de Política Internacional, v. 52, n. 2, p. 06, 2009.

18 ZIMMERMAN, Claus D. Toleration of temporary noncompliance: the systemic safety valve of WTO dispute settlement revisited. Trade, Law and Development, v. 3, n. 2, p. 382-406, 2011. 
dos membros é a de manterem um equilíbrio entre benefícios e ônus, ou seja, se os membros estão livres para agirem de forma inconsistente com as disposições dos acordos, desde que estejam dispostos a sofrerem a suspensão das concessões equivalentes. Esse sistema parece mais adequado para um regime que tem por finalidade simplesmente facilitar a resolução de litígios individuais, mas parece incompatível com um regime jurídico que visa produzir segurança e certeza para os membros. Portanto, se para o sistema é indiferente, se as leis dos seus membros estão em conformidade com as da organização ou se preferem suportar a suspensão das concessões, esta se convolou em obrigação primária dos membros. ${ }^{19}$

Diante disso, seria necessário conceber o direito da OMC como um conjunto de regras internacionais vinculativas, capaz de engendrar a responsabilidade internacional do estado e, assim, a obrigação de reparação do ato ilícito, nos termos dos princípios internacionalmente aceitos nesta matéria. Essa é a única forma de aumentar a segurança e a previsibilidade das relações comerciais, eliminando os incentivos existentes para a inobservância do sistema e fortalecendo suas regras para a implementação das obrigações. ${ }^{20}$

Por um lado, sem coação, as partes, inevitavelmente, não seguirão as suas decisões. ${ }^{21}$ Esse problema resulta, em parte, da mudança de um sistema baseado no poder para um sistema baseado em regras. Contudo, a "legalização" das disputas sob os auspícios da OMC termina quando o não cumprimento começa. ${ }^{22}$ Por outro lado, se a natureza jurídica da organização evoluir muito rápido, há o risco de afastar seus membros, o que poderia diminuir a confiança no regime internacional, mormente, caso a parte transgressora seja uma nação economicamente poderosa e, portanto, essencial para o

19 VAZQUEZ, Carlos M.; JACKSON, John H. Some reflections on compliance with WTO dispute settlement decisions. Law and Policy in International Business, v. 33, n. 4, p. 555568, 2002.

20 NGANGJOH, Yenkong; RIOS-HERRAN, Roberto. WTO dispute settlement system and the issue of compliance: multilateralizing the enforcement mechanism. Manchester Journal of International Economic Law, v. 1, n. 3, p. 15-30, 2004.

21 KHANSARI, Azar M. Searching for the perfect solution: international dispute resolution and the new world trade organization. Hastings International and Comparative Law Review, v. 20, n. 1, p. 189, 1996.

22 PAUWELYN, Joost H. Enforcement and countermeasures in the WTO: rules are rules - toward a more collective approach. American Journal of International Law, v. 94, p. 338, 2000. funcionamento do sistema de comércio mundial. Está muito claro que a OMC depende das boas intenções das partes. A Rodada Uruguai deu significativos passos na direção da criação de um efetivo tribunal internacional, com base no art. 23 do ESC. Entretanto, não obstante deva se desenvolver nesse sentido, a OMC é e continuará sendo, em um futuro próximo, uma criatura híbrida, tanto jurídica quanto diplomática em sua constituição. ${ }^{23}$ Consequentemente, um sistema orientado ao direito pode também trazer efeitos opostos aos desejados. Dessa maneira, admitindo-se que o cumprimento das obrigações será melhor para o sistema do que o não cumprimento, a questão é saber o que será mais eficaz na garantia do cumprimento, a adjudicação ou a negociação. ${ }^{24}$

\section{Fatores que influenciam o descumprimento das regras e das decisões da OMC pelos países desenvolvidos}

Vários fatores são responsáveis por uma maior desconformidade entre o comportamento dos países desenvolvidos e as regras da OMC, bem como pela incapacidade do OSC em determinar o cumprimento das suas decisões, quando esses países figuram na condição de partes perdedoras nas disputas: (i) situações de ausência de pressão da comunidade internacional; (ii) aspectos estruturais do sistema de solução de controvérsias; (iii) receio de perda de soberania..$^{25}$

Desde o antecessor da OMC, o GATT, cujo procedimento jurídico não era obrigatório, governos demandados sempre estiveram suscetíveis à pressão por parte da comunidade internacional, quando se chegava a um consenso de que a decisão era correta. ${ }^{26}$ Todavia, não há pressão internacional pelo cumprimento de uma decisão se um consenso não puder ser alcançado quanto à justiça dessa decisão. Dessa maneira, a descrença no processo pode tanto reduzir as pressões internacionais

23 DILLON JUNIOR., Thomas J. The World Trade Organization: a new legal order for world trade? Michigan Journal of International Law, v. 16, n. 2, p. 398, 1995.

24 DILLON JUNIOR, Thomas J. The World Trade Organization: a new legal order for world trade? Michigan Journal of International Law, v. 16, n. 2, p. 401. 1995.

25 BRIMEYER, Benjamin L. Bananas, beef, and compliance in the world trade organization: the inability of the WTO dispute settlement process to achieve compliance from superpower nations. Minnesota Journal of Global Trade, v. 10, p. 164, 2001.

26 HUDEC, Robert E. The new WTO dispute settlement procedure: an overview of the first three years. Minnesota Journal of Global Trade, v. 8, n. 1, p. 09, 1999. 
por seu cumprimento, quanto a aceitação pela comunidade internacional de um processo baseado em regras aumentar a conformidade a ele. ${ }^{2}$

A OMC foi criada para corrigir problemas gerados pela falta de um coeso conjunto de leis do GATT $^{28}$, especialmente frustrante para as partes contratantes. Os autores da OMC projetaram-na cuidadosamente para resolver essas deficiências organizacionais do GATT $^{29}$, cujas falhas no mecanismo de solução de controvérsias prejudicavam a coordenação do comércio internacional. Problemas processuais, inconsistências nas decisões do painel e um descompasso entre a conduta dos países e a legislação do GATT estimularam na comunidade internacional o desejo de um novo mecanismo de regulação comercial. ${ }^{30}$ De toda maneira, a mudança do GAT'T à OMC destinava-se a reforçar os princípios existentes, não a alterá-los, na esperança de se melhorar os níveis de cumprimento das regras e reduzir o uso de medidas comerciais unilaterais ${ }^{31}$, posto que se espalhou uma crença de que algumas regras do GAT'T não eram observadas e a aplicação de outras era imprópria. ${ }^{32}$

Uma das mais significativas diferenças entre os mecanismos de resolução de litígios da OMC e do GATT envolve a criação de painéis e a adoção de suas decisões. Cada sistema de solução de controvérsias começa com consulta e negociação entre as duas partes. Findo esse processo, se não houver êxito, ambos os sistemas permitem a formação de painéis para resolver a disputa. No âmbito do GAT'T, as partes tinham o

27 BRIMEYER, Benjamin L. Bananas, beef, and compliance in the world trade organization: the inability of the WTO dispute settlement process to achieve compliance from superpower nations. Minnesota Journal of Global Trade, v. 10, p. 166, 2001.

28 Pondera-se que, não há precisão na avaliação da eficácia de um sistema, no caso o GATT, sobre o qual não há dados suficientes quanto ao cumprimento de suas decisões. HUDEC, Robert E. The GATT legal system and world trade diplomacy . 2. ed. New York: Praeger Publishers, 1990. p. 95.

29 DILLON JUNIOR, Thomas J. The World Trade Organization: a new legal order for world trade? Michigan Journal of International Law, v. 16, n. 2, p. 355, 1995.

30 KHANSARI, AzarM. Searching for the perfect solution: international dispute resolution and the new world trade organization. Hastings International and Comparative Law Review, v. 20, n. 1, p. 189, 1996.

31 PRINCEN, Sebastiaan. EC compliance with WTO law: the interplay of law and politics. European Journal of International Law, v. 15, n. 3, p. 555-574, 2004.

32 MORA, Miquel Montana I. A GATT with teeth: law wins over politics in the resolution of international trade disputes. Columbia Journal of Transnational Law, v. 31, n. 1, p. 121, 1993. poder de bloquear a formação do painel ou impedir a adoção da decisão do painel, cuja adoção se dava apenas pelo voto unânime das partes envolvidas. Esse procedimento mudou no âmbito da OMC. Uma parte em uma controvérsia não pode mais bloquear a abertura de um painel ou vetar a adoção de uma decisão, que se tornou obrigatória. Assim que uma queixa é feita contra uma parte, esta pode evitar o painel por meio de negociação, porém não pode mais bloqueá-lo. ${ }^{33}$ Obviamente, o caráter vinculativo do procedimento de resolução de conflitos da OMC teve fortes efeitos. $\mathrm{O}$ objetivo principal em atribuir força jurídica às decisões do painel foi o de eliminar a morosidade e a falta de cumprimento. Contudo, sem a capacidade de bloquear uma decisão adversa, a morosidade e o não cumprimento tornaram-se alternativas jurídicas viáveis aos derrotados. Enquanto, por um lado, a nova natureza vinculativa do OSC serve para trazer mais negociações e menos painéis, por outro, pode resultar em maior descumprimento pelas partes perdedoras. ${ }^{34}$

Propostas de um mecanismo de apelação imbuído da retificação das decisões "fundamentalmente falhas" do painel ou da revisão de relatórios "errados" ou "incompletos" opunham-se aos temores de que causariam decisões finais ainda mais demoradas. ${ }^{35} \mathrm{Se}$ um governo violou um acordo: (i) ele sabe perfeitamente bem que houve uma violação; e (ii) ele o fez por causa de pressões políticas internas, as mesmas que atuarão sobre ele para que recorra ao tribunal de segunda instância, mesmo quando ele não deveria fazê-lo. É precisamente isso que preocupa em um sistema de solução de conflitos com um mecanismo de apelação: o estímulo ao recurso, materializado na revisão da decisão de cada painel. ${ }^{36}$

33 BRIMEYER, Benjamin L. Bananas, beef, and compliance in the world trade organization: the inability of the WTO dispute settlement process to achieve compliance from superpower nations. Minnesota Journal of Global Trade, v. 10, p. 164, 2001.

34 BRIMEYER, Benjamin L. Bananas, beef, and compliance in the world trade organization: the inability of the WTO dispute settlement process to achieve compliance from superpower nations. Minnesota Journal of Global Trade, v. 10, p. 165, 2001.

35 JOERGENS, Konstantin J. True appellate procedure or only a two-stage process? A view of the appellate body under the WTO dispute settlement understanding. Law and Policy in International Business, v. 30, n. 2, p. 195, 1999.

36 HORLICK, Gary. Dispute resolution mechanism: will the United States play by the rules? Journal of World Trade, v. 29, n. 2, p. $169,1995$. 
No caso de uma decisão negativa do painel, a parte pode interpor recurso. Se o recurso não for bemsucedido, a parte terá três opções: (i) o cumprimento da decisão da OMC; (ii) manutenção da prática ilegal, compensando a outra parte pelas perdas; ou (iii) completa desconsideração da decisão. A título de exemplo, os litígios carne e a bananas demonstram que, mesmo sem a capacidade de bloquear as decisões do painel, as partes vencidas optaram por criar longos atrasos e, depois, ignorar a decisão da OMC. Uma das razões para a criação do processo de apelação foi a de aliviar os efeitos da adoção automática das decisões do painel, todavia duas grandes preocupações foram observadas: (i) imprecisão e falta de especificidade da decisão; (ii) inconsistência e contradição na argumentação. Tais problemas com o processo de apelação podem minar a fé de uma das partes no sistema e, assim, tornar a não conformidade uma solução mais atraente. Dessa maneira, o processo de apelação também produziu um maior incumprimento. ${ }^{3}$

Um bom número de inconsistências resulta do raciocínio contraditório do órgão de apelação, às vezes, dentro do mesmo relatório. Dois casos ilustram o problema. No litígio Estados Unidos - Normas para gasolina modificada e convencional, a divisão do órgão de apelação, depois de ter afirmado a importância dos significados diferentes das palavras usadas no artigo XX do GATT, não fez a mesma distinção ao interpretar o caput desse artigo, afirmando que "discriminação arbitrária", "discriminação injustificável" e "restrição disfarçada" podem, consequentemente, ser lidos como sinônimos. No litígio Índia proteção de patente para produtos químicos farmacêuticos e agrícolas, o Órgão de Apelação afirmou que a Índia deveria suportar os efeitos dos direitos e obrigações consagrados no artigo 70.9 do TRIPS, a partir da data da entrada em vigor do Acordo Constitutivo da OMC (01 de janeiro de 1995), o que é, no mínimo, questionável se o órgão de apelação aplicou corretamente o artigo 31 da Convenção de Viena, por não considerar a sua remissão ao artigo 70.8, que prevê especificamente um período de transição para países em desenvolvimento. Esse dispositivo fica sem sentido sob essa interpretação. A jurisprudência revela que o órgão de apelação, por vezes, não

37 BRIMEYER, Benjamin L. Bananas, beef, and compliance in the world trade organization: the inability of the WTO dispute settlement process to achieve compliance from superpower nations. Minnesota Journal of Global Trade, v. 10, p. 165-166, 2001. conseguiu alcançar o desejado grau de consistência em sua análise. ${ }^{38}$

Outra questão das mais controversas no debate sobre a implementação dos acordos da Rodada Uruguai foi a dos possíveis efeitos sobre a soberania dos estados. ${ }^{39}$ Desde a criação da OMC, os países membros têm se preocupado com o fato de o sistema representar um risco para a soberania, ou seja, para o poder de agirem em nome dos seus cidadãos. Isso significa delegar a burocratas a capacidade de determinarem se as leis de um país violam a política internacional, impedindo os países de bloquear essa decisão e, ainda, retirando deles a capacidade de impor sanções unilaterais. Essas preocupações acabam, invariavelmente, por justificar o incumprimento de decisões contrárias, sob a alegação de que a parte vencida sente que sua soberania foi violada, remanescendo como única opção a não conformidade. Se os países virem a OMC não como um meio de resolver disputas, mas de infringir suas soberanias, o não cumprimento pode se tornar uma opção aceitável e os países membros simplesmente optarão por suportar as sanções, expressão do fracasso do órgão em ajudá-los a resolver disputas. De fato, se as nações poderosas preferirem as sanções ao cumprimento das decisões, a OMC revelará pouca serventia na arena de resolução de disputas. O litígio hormônio de carne viu a apreensão sobre a soberania se concretizar. A União Europeia afirmou que a decisão da OMC infringia o seu direito de determinar o nível de proteção que considera adequado para os seus próprios cidadãos. Em virtude dessa discordância, optou por um expediente de implementação responsável por atrasos no cumprimento e, por fim, pelo descumprimento da decisão. ${ }^{40}$

\section{Fatores que influenciam o descumprimento das regras e das decisões da omc pelos países em desenvolvimento}

O aumento dos acordos comerciais no âmbito da OMC, a necessidade do órgão resolver equitativamente disputas entre os países membros com grandes

38 JOERGENS, Konstantin J. True appellate procedure or only a two-stage process? A view of the appellate body under the WTO dispute settlement understanding. Law and Policy in International Business, v. 30, n. 2, p. 218-219, 1999.

39 HORLICK, Gary. WTO dispute settlement and the Dole commission.Journal of World Trade, v. 29, n. 6, p. 45-46, 1995.

40 BRIMEYER, Benjamin L. Bananas, beef, and compliance in the world trade organization: the inability of the WTO dispute settlement process to achieve compliance from superpower nations. Minnesota Journal of Global Trade, v. 10, p. 133-168, 2001. 
diferenças de poder político e econômico e os trabalhos do OSC, marcados pela transparência e neutralidade, contribuíram para o respeito às regras da organização e a expansão substancial do número de demandas, em relação ao regime anterior, envolvendo os países em desenvolvimento. ${ }^{41}$

Contudo, há diversos fatores que influenciam a desconformidade dos países em desenvolvimento às decisões do painel e do órgão de apelação da OMC: (i) a influência dramática da força política e econômica dos países desenvolvidos sobre o processo de solução de controvérsias; (ii) o descumprimento das decisões da OMC pelos países desenvolvidos; (iii) os aspectos técnicos do sistema de solução de controvérsias da OMC; (iv) a impossibilidade dos países em desenvolvimento de utilizarem o mecanismo da retaliação; (v) a falta de capacidade técnica e de recursos financeiros aos países em desenvolvimento. ${ }^{42}$

A primeira questão a ser considerada numa disputa é se o país envolvido é uma economia forte ou fraca. As disputas chegam até o ponto em que se define qual parte é a politicamente mais poderosa, o que desencoraja os países em desenvolvimento a demandarem os países membros do "Quad" — os EUA, a UE, o Japão e o Canadá - cujos interesses prevalecem. Há para os países em desenvolvimento uma frustração, quanto ao sistema de solução de controvérsias da $\mathrm{OMC}^{43}$, em virtude da tensão entre a preponderância do poder político, na prática, e a igualdade das regras, na teoria. Isso faz com que, na prática, o regime da OMC seja composto por estruturas "baseadas no poder", ditadas pelo "império

41 IERLEY, Douglas. Defining the factors that influence developing country compliance with and participation in the WTO dispute settlement system: another look at the dispute over bananas. Law and Policy in International Business, v. 33, p. 615652, 2002.

42 IERLEY, Douglas. Defining the factors that influence developing country compliance with and participation in the WTO dispute settlement system: another look at the dispute over bananas. Law and Policy in International Business, v. 33, p. 615652, 2002.

43 Ademais, os países em desenvolvimento sempre foram excluídos das discussões sobre o comércio internacional. O poder econômico também se desenrola em termos socioeconômicos, pois o impacto de uma disputa comercial entre um país desenvolvido e um país em desenvolvimento é certamente maior para este IERLEY, Douglas. Defining the factors that influence developing country compliance with and participation in the WTO dispute settlement system: another look at the dispute over bananas. Law and Policy in International Business, v. 33, p. 615652, 2002. da força”. Dois casos de destaque, Estados Unidos restrições às importações de algodão e Comunidade Europeia - regime de importação, venda e distribuição de bananas, em 2008, esclarecem as questões mais importantes e ilustram o que a participação no sistema de solução de controvérsias da OMC oferece aos países em desenvolvimento: por um lado, a possibilidade de processos contra um país desenvolvido, cujas práticas violam as regras do comércio internacional em seu próprio benefício; por outro, o fracasso do sistema de solução de controvérsias para resolver conflito. ${ }^{44} \mathrm{No}$ caso bananas, evidenciou-se a força do poder político e econômico dos EUA e da UE, que intimidaram e pressionaram a comunidade internacional, a fim de obterem uma decisão que lhes favorecesse. Dessa forma, os interesses das verdadeiras partes do litígio nações da América Latina, da África, do Caribe e do Pacífico - tornaram-se secundários e não apareceram na decisão final do painel da OMC. ${ }^{45}$

A despeito do estabelecimento de mais políticas de implementação no âmbito da $\mathrm{OMC}$, as nações menos desenvolvidas ainda enfrentam dificuldades, quando não falham por completo, em forçar as nações mais desenvolvidas a agirem em conformidade com as regras do comércio internacional. ${ }^{46}$ No entanto, a possibilidade de descumprimento por parte dos países em desenvolvimento surge, muitas vezes, como uma reação ao descumprimento dos países desenvolvidos. Sem o bom exemplo dos países desenvolvidos, os países em desenvolvimento ficam, naturalmente, menos relutantes em descumprir. O descumprimento dos países desenvolvidos estabelece um precedente muito ruim que incentiva o descumprimento dos países em desenvolvimento. ${ }^{47}$

44 IERLEY, Douglas. Defining the factors that influence developing country compliance with and participation in the WTO dispute settlement system: another look at the dispute over bananas. Law and Policy in International Business, v. 33, p. 615652, 2002.

45 KHANSARI, AzarM. Searching for the perfect solution: international dispute resolution and the new world trade organization. Hastings International and Comparative Law Review, v. 20, n. 1, p. 183-206, 1996.

46 KHANSARI, AzarM. Searching for the perfect solution: international dispute resolution and the new world trade organization. Hastings International and Comparative Law Review, v. 20, n. 1, p. 183-206, 1996.

47 IERLEY, Douglas. Defining the factors that influence developing country compliance with and participation in the WTO dispute settlement system: another look at the dispute over bananas. Law and Policy in International Business, v. 33, p. 615-652, 2002. 
Outrossim, há críticas técnicas ao sistema jurídico da OMC, cada vez mais sobrecarregado com questões com as quais ele não é capaz de lidar e que são desinteressantes aos países em desenvolvimento, a exemplo de propriedade intelectual, investimentos, entre outras. Ademais, o processo é muitas vezes visto como demorado e complicado, sendo necessárias reformas para acelerá-lo. E, ainda, suas decisões são consideradas demasiado legalistas para as necessidades reais das pessoas do mundo em desenvolvimento. Basta questionar, quem está se beneficiando com o sistema? ${ }^{48}$

Em certa medida, sem dúvida, a estrutura da OMC encoraja o cumprimento de suas decisões, por exemplo, por meio do mecanismo da retaliação cruzada. ${ }^{49} \mathrm{O}$ cumprimento das decisões do OSC é considerado um importante, talvez o mais importante, dado na avaliação da eficácia do ESC. ${ }^{50}$ Entretanto, a prática de retaliações comerciais autorizadas por mecanismos jurisdicionais, como instrumento de política comercial internacional é foco de críticas à efetividade e ao modo de funcionamento do OSC..$^{51}$

A imposição de sanções, geralmente, fere os interesses comerciais de ambas as partes, por consequência, a capacidade desse mecanismo de induzir o cumprimento está longe de ser certa..$^{52} \mathrm{~A}$ retaliação nunca foi aplicada sob as regras do GATT e, no âmbito da OMC, em apenas quatro contenciosos: Comunidade Europeia regime de importação, venda e distribuição de bananas; Comunidade Europeia Hormônios; Estados Unidos Tratamento tributário para "venda de corporações estrangeiras"; Estados Unidos Lei de 2000, sobre dumping e compensação de

48 IERLEY, Douglas. Defining the factors that influence developing country compliance with and participation in the WTO dispute settlement system: another look at the dispute over bananas. Law and Policy in International Business, v. 33, p. 615652, 2002.

49 HORLICK, Gary. WTO dispute settlement and the Dole commission. Journal of World Trade, v. 29, n. 6, p. 45-48, 1995.

50 VAZQUEZ, Carlos M.; IACKSON, John H. Some reflections on compliance with WTO dispute settlement decisions. Law and Policy in International Business, v. 33, n. 4, p. 555568. 2002.

51 VARELLA, M. D. Efetividade do Órgão de Solução de Controvérsias da Organização Mundial do Comércio: uma análise sobre os seus doze primeiros anos de existência e das propostas para seu aperfeiçoamento. Revista Brasileira de Política Internacional, v. 52, n. 2, p. 05-21, 2009.

52 MCGIVERN, Brendan P. Seeking compliance with WTO rulings: theory, practice and alternatives. International Lawyer $(A B A)$, v. 36, n. 1, p. 141-158, 2002. subsídio. A retaliação no caso Hormônios não mudou a política comercial europeia. E, mesmo nos outros três casos, conquanto seja indiscutível que a retaliação teve algum efeito sobre a resolução desses conflitos, é difícil identificá-la como o fator principal. ${ }^{53}$

Especificamente, é questionável se a retaliação cruzada seria um mecanismo eficaz para garantir o cumprimento nos casos em que o demandado é um país grande e rico e o demandante é um país pequeno e pobre, cujo total de importações corresponda a uma parte insignificante do comércio internacional, destarte, uma retaliação cruzada pode representar nada mais do que "a picada de um mosquito em um elefante", em outras palavras, não é suficientemente eficaz no sentido de encorajar o país violador a adaptar suas medidas em conformidade com as regras internacionais. ${ }^{54}$ Por exemplo, na visão do Departamento de Comércio dos EUA (USTR), se os norte-americanos perdem um painel, podem cumprir as regras de resolução de disputas da OMC, aceitando a retaliação. Sem dúvida, se a OMC considerou que houve violação, há uma contínua obrigação, todavia, com a retaliação, também há uma mitigação, é claro. A título de comparação, um relatório do General Accounting Office (GAO) afirma que, com as exceções importantes da UE, do Japão e do Canadá, nenhum membro do antigo GATT tinha força econômica para retaliar unilateralmente os EUA. Isso explica, do ponto de vista do GAO, por que, com frequência, os países simplesmente aceitavam o descumprimento norte-americano, em vez de retaliá-lo. ${ }^{55}$

De sua banda, muitos países em desenvolvimento não têm sequer a opção de escolherem o descumprimento das recomendações do OSC, pois suas fracas economias não suportariam retaliar as economias dos países desenvolvidos. O exercício do mecanismo da retaliação pelos países em desenvolvimento, economicamente frágeis, como meio principal de se determinar a conformidade dos países desenvolvidos, não é uma opção prática. O custo econômico da retirada de concessões comerciais, dada a relevância das importações e o potencial aumento

53 DAVEY, William J. Compliance problems in WTO dispute settlement. Cornell International Law Journal, v. 42, n. 1, p. 119-128, 2009.

54 DILLON JUNIOR, Thomas J. The World Trade Organization: a new legal order for world trade? Michigan Journal of International Law, v. 16, n. 2, p. 349-402, 1995.

55 HORLICK, Gary. Dispute resolution mechanism: will the United States play by the rules? Journal of World Trade, v. 29, n. 2, p. 163-172, 1995. 
dos custos, tornam inevitáveis os danos à economia dos países em desenvolvimento que tomam medidas de retaliação. Além disso, há dificuldades quanto à escolha dos produtos e ao nível de retaliação. ${ }^{56} \mathrm{Em}$ que pese seja eficaz quando usada por um membro importante da OMC, a retaliação não é um remédio adequado para os países pequenos, e, certamente, por isso, nunca a utilizaram, mesmo quando autorizados pela OMC. ${ }^{57}$

Portanto, a verdadeira questão para o mundo em desenvolvimento, incluindo as economias em transição, é saber o que mais interessa. Considerar expedientes gerados pelos acordos celebrados no âmbito da OMC, a exemplo da retaliação cruzada, como benéficos a esses países é algo controverso. ${ }^{58}$

Ademais, o direito à retaliação cruzada concedido a um país em desenvolvimento pelo êxito em uma demanda sob os auspícios da OMC, a exemplo do que se deu com o Equador no caso Bananas, é uma vitória jurídica que se transforma em um problema político para os países em desenvolvimento, qual seja, o risco dos países desenvolvidos responderem à retaliação cruzada retirando o Sistema Geral de Preferências (SGP). ${ }^{59} \mathrm{O}$ medo de contramedidas não autorizadas ou maquiadas, materializadas na suspensão do SGP, é um dos principais motivos da não utilização de todas as medidas possíveis e autorizadas pelo ESC. ${ }^{60}$

De acordo com os artigos 22.1 - 22.2 do ESC, a compensação - embora também não produza diretamente o cumprimento - é uma alternativa à retaliação, no prazo de vinte dias após expirado o

56 IERLEY, Douglas. Defining the factors that influence developing country compliance with and participation in the WTO dispute settlement system: another look at the dispute over bananas. Law and Policy in International Business, v. 33, p. 615652, 2002.

57 DAVEY, William J. Compliance problems in WTO dispute settlement. Cornell International Law Journal, v. 42, n. 1, p. 119-128, 2009.

58 DILLON JUNIOR, Thomas J. The World Trade Organization: a new legal order for world trade? Michigan Journal of International Law, v. 16, n. 2, p. 349-402, 1995.

59 IERLEY, Douglas. Defining the factors that influence developing country compliance with and participation in the WTO dispute settlement system: another look at the dispute over bananas. Law and Policy in International Business, v. 33, p. 615652, 2002.

60 VARELLA, M. D. Efetividade do Órgão de Solução de Controvérsias da Organização Mundial do Comércio: uma análise sobre os seus doze primeiros anos de existência e das propostas para seu aperfeiçoamento. Revista Brasileira de Política Internacional, v. 52, n. 2, p. 05-21, 2009. período de tempo razoável. Destacam-se os seguintes contenciosos notificados de solução mutuamente aceitável: Japão impostos sobre bebidas alcoólicas, 1998 (o Japão compensou comercialmente o Canadá); Turquia Restrições sobre produtos têxteis e roupas importadas, 2001 (a Turquia compensou comercialmente a Índia); Acordo sob o artigo 21.3 (b) do ESC, Estados Unidos medidas de salvaguarda definitivas sobre as importações de tubulação de carbono soldado de alta qualidade da Coreia, 2002 (os Estados Unidos compensaram comercialmente a Coreia); Estados Unidos - Seção 110 (5) da Lei de Direitos Autorais norte-americana, 2003 (os Estados Unidos ofereceram compensação monetária pelos três anos de não implementação). ${ }^{61}$

Em que pesem esses problemas, é inegável que o regime de comércio internacional da OMC deu um passo decisivo em direção ao legalismo, com destaque para o importante papel desempenhado pelos mecanismos de resolução de litígios, portanto uma adequada assistência jurídica em disputas comerciais tornou-se essencial. Ser capaz de resolver questões que incidem sobre os seus direitos é a única maneira do estado desempenhar um papel e beneficiar-se do complexo regime de comércio internacional. ${ }^{62}$ Não há dúvida de que é necessário capacitar os representantes dos países em desenvolvimento e estimulá-los a participarem ainda mais ativamente desse sistema como a única forma de aumentarem suas experiências e ganharem as disputas. Há países que sequer possuem um ministério dedicado aos assuntos do comércio internacional. Sem saber como a OMC funciona, como os painéis realizam audiências e tomam decisões, é impossível tirar proveito do seu sistema de solução de controvérsias, nem mesmo compreender os benefícios do ESC. Ademais seria importante para alavancar os países em desenvolvimento para um novo ciclo de reforma do ESC. A falta de capacidade técnica está diretamente relacionada à incapacidade de identificar violações comerciais e iniciar casos, afetando posições de negociação em disputas. A mera ameaça de utilizar o sistema já aumenta o poder de barganha desses países. ${ }^{63}$

61 DAVEY, William J. Compliance problems in WTO dispute settlement. Cornell International Law Journal, v. 42, n. 1, p. 119-128, 2009.

62 MCBRIDE, Thaddeus. Rejuvenating the WTO: Why the U.S. must assist developing countries in trade disputes. International Legal Perspectives, v. 11, n. 1, p. 6-102, 1999.

63 IERLEY, Douglas. Defining the factors that influence developing country compliance with and participation in the 
O direito da OMC também pode ter efeitos sem uma decisão formal ou mesmo sem que um caso seja levado ao OSC. A ameaça de recurso ao sistema pode assegurar o cumprimento antes de surgir efetivamente um litígio. De fato, a conformidade com a legislação da OMC será mais pronunciada nos casos em que uma decisão não formal é emitida, isto é, o cumprimento da legislação do GATT / OMC é menos provável em casos que envolvem uma sentença. ${ }^{64} \mathrm{Na}$ conclusão da Rodada Uruguai, muitos funcionários estavam otimistas de que a simples ameaça de retaliação automática serviria como uma ferramenta poderosa para forçar as partes recalcitrantes a cumprirem com suas obrigações. No entanto, houve disputas em que a ameaça de utilização da retaliação ou o seu efetivo uso não foram suficientes, em que pese o pequeno número de $\operatorname{casos}^{65} \mathrm{O}$ uso pelos governos das reclamações legais como tática de negociação, sem a intenção de realmente litigar, é, ademais, uma das razões por que o novo procedimento no âmbito da OMC resultou em um menor número de painéis. ${ }^{66} \mathrm{Nessa}$ perspectiva, as críticas às deficiências de conformidade seriam insensatas, pois a suspensão de concessões raramente ocorre, já que são raros os casos de incumprimento após o curso completo do litígio e, mesmo nesses casos, o contencioso favorece os reclamantes durante as negociações comerciais. ${ }^{67}$

Não obstante a importância de uma representação jurídica capacitada, permanece difícil para os países em desenvolvimento arcar com essa assistência. Destarte, uma substancial assistência jurídica deve lhes ser fornecida, caso contrário, as nações desenvolvidas permanecerão sendo as principais beneficiárias do comércio mundial ${ }^{68}$. E, por isso, esse grupo de elite é

WTO dispute settlement system: another look at the dispute over bananas. Law and Policy in International Business, v. 33, p. 615652, 2002.

64 PRINCEN, Sebastiaan. EC compliance with WTO law: the interplay of law and politics. European Journal of International Law, v. 15, n. 3, p. 555-574, 2004.

65 MCGIVERN, Brendan P. Seeking compliance with WTO rulings: theory, practice and alternatives. International Lanyer $(A B A)$, v. 36, n. 1, p. 141-158, 2002.

66 BRIMEYER, Benjamin L. Bananas, beef, and compliance in the world trade organization: the inability of the WTO dispute settlement process to achieve compliance from superpower nations. Minnesota Journal of Global Trade, v. 10, p. 133-168, 2001.

67 COLARES, Juscelino F. Thelimits of WTO adjudication: is compliance the problem? Journal of International Economic Law, v. 14, n. 2, p. 403-436, 2011.

68 Será interessante observar ao longo do tempo se os dados empíricos confirmam a suspeita de que esse comportamento o que mais tem a perder. Se não agir rapidamente para ajudar o mundo em desenvolvimento, eles só terão a si mesmos para culpar por suas perdas.$^{69}$ Por essas razões, a resolução de litígios internacionais tem se revelado como o resultado mais de manobras políticas do que de uma verdadeira preocupação em melhorar as condições do comércio internacional. ${ }^{70}$ Diante disso, podem ser endereçadas críticas à $\mathrm{OMC}$ e aos países desenvolvidos por seus parcos esforços para atender as necessidades de assistência técnica dos países em desenvolvimento, a começar pela ausência da questão nos próprios acordos da OMC. ${ }^{71}$ Dentro das obrigações claras que o Acordo da OMC cria para estados, a parte pertinente aos países em desenvolvimento deve ser revitalizada. ${ }^{72}$

Intimamente ligada à capacidade técnica está a questão dos recursos financeiros, ou seja, fundos para iniciar investigações sobre violações comerciais. Muitas vezes, é o setor privado desses países que ajuda a cobrir os custos associados a ações judiciais da OMC. O custo é o fator mais importante, representa a maior dificuldade para a participação no sistema de solução de controvérsias e é responsável por muitos países em desenvolvimento somente atuarem no processo de disputa quando forçados.?

tornou-se discriminatório, ficando os países ricos — aqueles mais capazes de arcar com o custo interno ou externo de se defenderem em litígios no âmbito da OMC — em uma melhor posição do que os países pobres HORLICK, Gary; COLEMAN, Judith. The compliance problems of the WTO. Arizona Journal of International and Comparative Law, v. 24, n. 1, p. 141-148, 2007.

69 MCBRIDE, Thaddeus. Rejuvenating the WTO: Why the U.S. must assist developing countries in trade disputes. International Legal Perspectives, v. 11, n. 1, p. 6-102, 1999.

70 KHANSARI, AzarM. Searching for the perfect solution: international dispute resolution and the new world trade organization. Hastings International and Comparative Law Review, v. 20, n. 1, p. 183-206, 1996.

71 IERLEY, Douglas. Defining the factors that influence developing country compliance with and participation in the WTO dispute settlement system: another look at the dispute over bananas. Law and Policy in International Business, v. 33, p. 615652, 2002.

72 MCBRIDE, Thaddeus. Rejuvenating the WTO: Why the U.S. must assist developing countries in trade disputes. International Legal Perspectives, v. 11, n. 1, p. 6-102, 1999.

73 IERLEY, Douglas. Defining the factors that influence developing country compliance with and participation in the WTO dispute settlement system: another look at the dispute over bananas. Law and Policy in International Business, v. 33, p. 615652, 2002. 
Por outro lado, em que pese os países apresentarem capacidades e recursos díspares, o que implica o ESC ser muito menos eficaz para os países em desenvolvimento do que para os países desenvolvidos, a alegação da sua ilegitimidade por conta dessa disparidade de poder negligencia o fato de que, na sua ausência, essa desigualdade seria ainda maior. A falha do ESC não reside na criação de um sistema pautado na igualdade de tratamento dos membros - a propósito, uma importante medida da legitimidade de um sistema jurídico - ao contrário, reside em não ir além e não buscar reduzir a desigualdade de fato reinante no plano internacional. Nações poderosas terão mais poder de violar suas obrigações internacionais com impunidade, enquanto exigem das demais o cumprimento delas. Sistemas jurídicos procuram diminuir tais disparidades de poder ou, pelo menos, minimizar sua importância na distribuição e execução de direitos e deveres, e, mesmo em sistemas domésticos, as disparidades nunca são totalmente neutralizadas. ${ }^{74}$

\section{Formas de descumprimento das regras e das decisões da OMC}

Todos os dias, os governos de todo o mundo agem em conformidade com a OMC e, antes dela, provavelmente até com mais frequência, agiam de acordo com o GATT. No entanto, nas ocasiões raras em que governos nacionais decidem, ao contrário, não cooperar, a OMC tem se mostrado um instrumento fraco. Essa não-conformidade tende a assumir, pelo menos, quatro formas: (i) descumprimento prévio; (ii) descumprimento temporário; (iii) morosidade; e (iv) descumprimento, aberto e disfarçado. ${ }^{75}$

A julgar a partir da amostra oferecida pelos casos levados ao mecanismo de solução de controvérsias da OMC, praticamente todos os principais membros adotaram medidas inconsistentes com as regras da organização, considerando que, na pior das hipóteses, seriam condenados por uma decisão definitiva do órgão de apelação, em um litígio que duraria de três a quatro anos, antes de terem de cumprir o que previamente acordaram. Isso tanto foi feito pelos maiores como

74 VAZQUEZ, Carlos M.; ذACKSON, John H. Some reflections on compliance with WTO dispute settlement decisions. Law and Policy in International Business, v. 33, n. 4, p. 555568. 2002.

75 HORLICK, Gary; COLEMAN, Judith. The compliance problems of the WTO. Arizona Journal of International and Comparative Law, v. 24, n. 1, p. 141-148, 2007. pelos menores atores. Com efeito, a Carta da OMC foi reescrita diante da não aplicação das obrigações do órgão por um período de três a quatro anos. O exemplo mais óbvio é o caso "zerar", envolvendo a Índia contra a Comunidade Europeia, decidido em favor da Índia pelo órgão de apelação em $2001 .^{76}$

Embora os mecanismos de solução de controvérsias da OMC não tenham sido concebidos para incentivar violações, o sistema existente acomoda, de facto, pelo menos, o descumprimento temporário. $\mathrm{O}$ atual modelo do mecanismo de solução de controvérsias da OMC, operando temporariamente como um sistema de "violação e compensação", cumpre um papel crucial como válvula de segurança sistêmica para raros cenários em que é impossível os membros da OMC cumprirem as recomendações e decisões do OSC dentro do "prazo razoável de tempo", conforme previsto no artigo 21.3 do ESC. Mesmo ao término desse período marcado por circunstâncias excepcionais, o cumprimento não deve se dar a qualquer custo e o país membro pode "comprar" um tempo adicional. Essa regra, todavia, certamente não tem impedido alguns membros da OMC de apresentarem dezenas de relatórios contendo poucas novidades sobre o progresso da implementação doméstica, a exemplo do $107^{\circ}$ relatório apresentado pelo EUA, em 14 de outubro de 2011, sobre a disputa EUA - Seção 211 Lei de Recursos dos Ônibus, de 1998, em que, de maneira similar aos relatórios anteriores, os EUA simplesmente afirmam que continuam trabalhando na busca de uma solução para a questão.

Os estudiosos do direito internacional devem abandonar a ilusão de um mundo regido por leis obrigatórias proibitivas de barreiras comerciais. A existência de barreiras comerciais revela exceções de conteúdo e atenuações de procedimentos das leis que as proíbem. No mundo real há circunstâncias em que um cumprimento integral não é sequer desejado. ${ }^{78}$

Mesmo admitindo, caridosamente, que todos os membros da OMC ajam de boa-fé no cumprimento de suas obrigações e que, portanto, eles só descobrem que

76 HORLICK, Gary; COLEMAN, Judith. The compliance problems of the WTO. Arizona Journal of International and Comparative Law, v. 24, n. 1, p. 141. 2007.

77 ZIMMERMAN, Claus D. Toleration of temporary noncompliance: the systemic safety valve of WTO dispute settlement revisited. Trade, Law and Development, v. 3, n. 2, p. 382-406, 2011.

78 TRACHTMAN, Joel P. Bananas, direct effect and compliance. European Journal of International Law, v. 10, n. 4, p. 655-678, 1999. 
estão em violação depois de uma decisão do órgão de apelação, há inúmeros casos em que o processo posterior a essa decisão estende-se por anos. Mais uma vez, isso não envolve poucos países membros. É óbvio que vários governos decidiram burlar o sistema e estender o descumprimento por tanto tempo quanto possível. E isso sem considerar os numerosos atrasos nos processos judiciais antes das decisões do órgão de apelação é assustador ouvir advogados dos países membros afirmarem, claramente, que estão procrastinando o processo o máximo que podem..$^{7}$ De fato, empresas têm identificado a não conformidade e os atrasos como razões para não usar o sistema de solução de controvérsias da OMC, o que levanta sérias preocupações futuras. ${ }^{80}$

Há, ainda, um número crescente de decisões em que os membros, abertamente, escolheram correr o risco de serem retaliados ao invés de cumpri-las, por exemplo, no caso Comunidade Europeia - Hormônios, de 1998, em que nem mesmo a retaliação levou à conformidade, tampouco compensou (e nem poderia) os exportadores prejudicados pelas medidas europeias consideradas incompatíveis com as regras da OMC. Nenhum outro descumprimento poderia ser assim tão aberto. ${ }^{81}$

A seu turno, a título de exemplo de descumprimento disfarçado, o site da OMC relaciona como um sucesso o caso EUA chumbo e bismuto, posto que, em síntese, o órgão de apelação decidiu e o país demandado cumpriu. Todavia, não registra em nenhum lugar o pagamento de milhões de dólares à companhia envolvida. ${ }^{82}$ Em outro

79 HORLICK, Gary; COLEMAN, Judith. The compliance problems of the WTO.Arizona Journal of International and Comparative Law, v. 24, n. 1, p. 141-148, 2007.

80 DAVEY, William J. Compliance problems in WTO dispute settlement. Cornell International Law Journal, v. 42, n. 1, p. 119-128, 2009.

81 Todavia, não se deve olvidar que, conquanto a responsabilidade de um membro em relação às obrigações da OMC pareça mais limitada do que a de um estado sob o direito internacional geral, indiscutivelmente, a conformidade às regras e decisões da OMC configura uma obrigação de direito internacional VAZQUEZ, Carlos M.; JACKSON, John H. Some reflections on compliance with WTO dispute settlement decisions. Law and Policy in International Business, v. 33, n. 4, p. 555568. 2002. Com base na linguagem do ESC, na prática do GATT e nos trabalhos preparatórios das negociações da Rodada Uruguai, é possível dizer que a recomendação de um relatório de um painel constitui uma obrigação jurídica internacional JACKSON, John H. The WTO dispute settlement understanding: misunderstandings on the nature of legal obligation. The American Journal of International Law, v. 91, n. 1, p. 60-64, 1997.

82 HORLICK, Gary; COLEMAN, Judith. The compliance exemplo, a disputa entre Canadá e Brasil, sobre os subsídios dos jatos, revela potenciais problemas com os cálculos das contramedidas, porque a intenção declarada de tais medidas não era punir ou compensar, mas induzir o cumprimento. Nesse papel, entretanto, essas medidas preventivas não foram bem-sucedidas. Esse caso também pode forçar a OMC a encarar a espinhosa questão de saber se o ESC foi concebido para fornecer um sistema verdadeiramente vinculativo, posto que, no final do litígio, restou um grave problema, a tentativa das partes evitarem o cumprimento das decisões do OSC pela "reestruturação" de seus programas de subsídio e a continuação da concessão dos subsídios no âmbito dos programas "novos", sob a alegação de que são compatíveis. ${ }^{83} \mathrm{~A}$ avaliação da eficácia do ESC deve levar em conta a indução ao cumprimento das decisões dos painéis e do órgão de apelação, responsável pela clareza das obrigações dos membros, bem como pela redução dos conflitos internacionais, em última instância. ${ }^{84}$

\section{Análise de dados e estatísticas pertinentes ao cumprimento das regras e das decisões da OMC}

Uma pesquisa ${ }^{85}$ realizada em 2007, sobre as respostas dos países membros às decisões da $\mathrm{OMC}$, aponta que, das 98 decisões finais, proferidas desde 1996, o painel ou o órgão de apelação entendeu que houve violações às regras da $\mathrm{OMC}$ em 85 casos $(85,8 \%)$. Isso quer dizer que não foram encontradas violações em 13 casos. Dos 85 casos de violações, o prazo para o cumprimento ainda não havia se exaurido em 6 deles, e o estado de conformidade de 2 não era claro, deixando 77 casos para a continuação da análise. Dos 77 casos, 53 (68,8\%) terminaram em aparente cumprimento, o que inclui o cumprimento após ameaças de retaliação. Em 19 casos (24,6\%), o país transgressor fez gestos de cumprimento: cumprimento parcial (revisão de algumas, mas não de

problems of the WTO.Arizona Journal of International and Comparative Law, v. 24, n. 1, p. 141-148, 2007.

83 SULLIVAN, Helena D. Regional Jet Trade Wars: Politics and Compliance in WTO Dispute Resolution. Minnesota Journal of Global Trade, v. 12, p. 71-108, 2003.

84 VAZQUEZ, Carlos M.; JACKSON, John H. Some reflections on compliance with WTO dispute settlement decisions. Law and Policy in International Business, v. 33, n. 4, p. 555568. 2002.

85 Para uma descrição mais detalhada dos casos e membros envolvidos, consultar: HORLICK, Gary; COLEMAN, Judith. The compliance problems of the WTO. Arizona Journal of International and Comparative Law, v. 24, n. 1, p. 141-148, 2007. 
todas as medidas) em 8 casos; cumprimento discutível (em que o país demandado alega ter cumprido, mas o demandante contesta o cumprimento) em 6 casos; acordos tíbios em 5 casos (dos quais 4 estão relacionados à pendência entre EUA e Canadá sobre as madeiras coníferas. Finalmente, 6 dos casos $(6,1 \%)$ resultaram em descumprimento descarado, tolerado, a contragosto, em todos eles, exceto no litígio Comunidade Europeia - Hormônios. ${ }^{86}$

Em outro trabalho sobre os mesmos doze primeiros anos de existência da OMC, chega-se ao índice de cumprimento de $83 \%$ dos contenciosos. Todavia, os $17 \%$ restantes são interpretados de maneira diferente, como contenciosos anteriores à criação da OMC, sendo o novo sistema utilizado para tentar reverter situações já consolidadas nos estados. A título de exemplo, os contenciosos sobre o regime de importação de bananas, pertinente a dezenas de países membros e polêmico desde os anos 1970; e sobre os hormônios na carne bovina norte-americana, cuja implementação da decisão da OMC nos estados-membros da União Europeia tornou-se politicamente inoportuna devido às crises sanitárias. ${ }^{87}$

O índice de cumprimento no âmbito da OMC é muito bom para um sistema internacional de solução de controvérsias entre estados ${ }^{88}$. Os bons números são devidos, principalmente, à boa-fé e ao desejo dos membros de verem o sistema de solução de controvérsias funcionar de forma eficaz. Os usuários mais ativos do sistema são os atores que se repetem tanto como demandantes quanto como demandados. Portanto, é do interesse deles que o sistema funcione eficazmente e, na maioria dos casos, ele realmente funciona. ${ }^{89} \mathrm{Em}$ termos gerais, o nível de cumprimento das decisões

86 HORLICK, Gary; COLEMAN, Judith. The compliance problems of the WTO. Arizona Journal of International and Comparative Law, v. 24, n. 1, p. 141-148, 2007.

87 VARELLA, M. D. Efetividade do Órgão de Solução de Controvérsias da Organização Mundial do Comércio: uma análise sobre os seus doze primeiros anos de existência e das propostas para seu aperfeiçoamento. Revista Brasileira de Política Internacional, v. 52, n. 2, p. 05-21, 2009.

88 A título de comparação, nos contenciosos da Corte Internacional de Justiça (CIJ), o percentual de cumprimento das decisões é de 68\% GINSBURG, Tom; MCADAMS, Richard H. Adjudicating in anarchy: an expressive theory of international dispute resolution. William and Mary Law Review, v. 45, n. 4, p. 1229-1340, 2004.

89 DAVEY, William J. Compliance problems in WTO dispute settlement. Cornell International Law Journal, v. 42, n. 1, p. 119-128, 2009. da OMC tem sido muito bom. A maioria dos países, na maioria dos casos, implementou a maior parte dos relatórios do painel e do órgão de apelação, devido ao interesse dos membros em promover a integridade de um sistema baseado em regras, mesmo que isso signifique, de vez em quando, aceitar e implementar uma decisão desagradável. ${ }^{90}$

Uma taxa de 6,1\% de não conformidade não parece mesmo nada ruim. Porém, a maior parte é cumulativa, ou seja, a maioria dos casos não desaparece, o que significa um crescente descumprimento. ${ }^{91} \mathrm{~A}$ título de comparação, no âmbito do GATT ${ }^{92}$, o sistema de solução de controvérsias não funcionou em 12\% dos 207 casos registrados, o que foi suficiente para abalar a credibilidade do Acordo e pavimentar as contundentes mudanças produzidas na Rodada Uruguai. ${ }^{93}$ Nesse contexto, os $25 \%$ de cumprimento não integral somados aos atrasos para se atingir o pleno cumprimento, em outros casos, sugerem a necessidade de reformas na OMC. ${ }^{94}$

Em contraponto, é temerário comparar a eficácia do regime de solução de controvérsias da OMC com o regime anterior - cujas decisões eram proferidas somente pelos painéis de solução de controvérsias porquanto a existência de um sistema de solução de controvérsias mais rigoroso pode incentivar os membros a litigarem, possibilidade que antes não tinham..$^{95}$

De toda maneira, o quadro não é assim tão róseo se olharmos além das estatísticas gerais e considerarmos a "qualidade do cumprimento", isto é, a forma como

90 MCGIVERN, Brendan P. Seeking compliance with WTO rulings: theory, practice and alternatives. International Lawyer $(A B A)$, v. 36, n. 1, p. 141-158, 2002.

91 HORLICK, Gary; COLEMAN, Judith. The compliance problems of the WTO. Arizona Journal of International and Comparative Law, v. 24, n. 1, p. 141-148, 2007.

92 O GATT revelou-se um fórum adequado para as disputas. Prova disso é que, mesmo no âmbito do Acordo EUA - Canadá, dotado de mecanismos formais de resolução de conflitos, ambos os países, em várias ocasiões, preferiram ir ao GATT HORLICK, Gary. WTO dispute settlement and the Dole commission. Journal of World Trade, v. 29, n. 6, p. 45-48, 1995.

93 HUDEC, Robert E. Enforcing international trade law: the evolution of the modern GATT legal system. Salem, N. H.: Butterworth Legal Publishers, 1993.

94 HORLICK, Gary; COLEMAN, Judith. The compliance problems of the WTO. Arizona Journal of International and Comparative Law,v. 24, n. 1, p. 141-148, 2007.

95 VAZQUEZ, Carlos M.; JACKSON, John H. Some reflections on compliance with WTO dispute settlement decisions. Law and Policy in International Business, v. 33, n. 4, p. 555-568. 2002. 
a decisão da OMC foi implementada e se a violação cessou e não foi modificada ou substituída por outra medida, e o "tempo de cumprimento", ou seja, se a ação de execução foi feita dentro de um razoável período de tempo fixado para a execução e se o tempo decorrido no painel e no órgão de apelação respeitou os padrões especificados no ESC..$^{96}$ De modo geral, na primeira década de resolução de litígios, no âmbito da OMC, o cumprimento das decisões foi tempestivo, respeitando-se o tempo razoável para a implementação definida, entretanto, muitas vezes, o processo levou tanto tempo que a implementação não foi muito significativa em termos práticos ${ }^{97}$. Em $75 \%$ dos casos de defesa comercial, o resultado foi a modificação da medida contestada, todavia depois de um longo decurso temporal. Os países que menos cumpriram as decisões em tempo hábil foram a UE, o Canadá, o Japão, a Austrália e, principalmente, os EUA, a uma taxa de $50 \%$, enquanto os países em desenvolvimento atingiram um índice de mais de $80 \%{ }^{98}$

\section{Propostas e perspectivas de aprimoramento do cumprimento das decisões da OMC}

Diante dos registros do sistema de solução de controvérsias da OMC, há um espaço considerável para a melhoria da conformidade existente. ${ }^{99}$ Uma diluição da soberania poderia facilitar o cumprimento. Se as negociações comerciais fossem realizadas em bloco não com base no interesse exclusivo de cada um dos países, senão esse interesse como parte de um grupo as decisões poderiam ser tomadas fora dos domínios da soberania, ou seja, os interesses econômicos colocados à

96 DAVEY, William J. Compliance problems in WTO dispute settlement. Cornell International Law Journal, v. 42, n. 1, p. 119-128, 2009.

97 Ademais, o grau de cumprimento tende a ser melhor em disputas exclusiva ou principalmente comerciais. Problemas de implementação são mais propensos a surgir em casos que também envolvem preocupações não comerciais. Por exemplo, o compromisso da CE de desenvolver a economia das de excolônias europeias na África, no Caribe e no Pacífico (ACP) dificultou o cumprimento integral das decisões da OMC na disputa Bananas MCGIVERN, Brendan P. Seeking compliance with WTO rulings: theory, practice and alternatives. International Lawyer (ABA), v. 36, n. 1, p. 141-158, 2002.

98 DAVEY, William J. Compliance problems in WTO dispute settlement. Cornell International Law Journal, v. 42, n. 1, p. 119-128, 2009 .

99 DAVEY, William J. Compliance problems in WTO dispute settlement. Cornell International Law Journal, v. 42, n. 1, p. 119-128, 2009. frente dos políticos. ${ }^{100}$ Nessa esteira, o poder da própria OMC em demandar, aplicar retaliações multilaterais e fiscalizar os países mais poderosos pode revelar-se mais eficaz. ${ }^{101} E$ certamente verdade que os países em desenvolvimento têm muito menos poder prático para induzir o cumprimento pelos países desenvolvidos do que o contrário. Destarte, para minimizar esse problema, merece séria consideração o estabelecimento de um mecanismo que, por exemplo, permita contramedidas impostas coletivamente. ${ }^{102}$ A possibilidade de medidas defensivas coletivas no contexto da OMC certamente teria um efeito positivo em termos da melhoria do grau e do tempo em que as recomendações e decisões do OSC são implementadas. Além disso, teria um efeito positivo sobre a eliminação de alguns dos incentivos existentes para o não cumprimento, quando o poder de retaliação bilateral de uma parte não é grande. ${ }^{103}$

A noção de "retaliação coletiva" foi levantada pela primeira vez no âmbito do GATT, em meados da década de 1960, quando uma série de países em desenvolvimento argumentou que eles não tinham a capacidade de infligir comercialmente retaliação significativa nas economias dos países desenvolvidos. Portanto, propugnaram a adoção de um novo sistema que permitisse a todos retaliar. Desde então, a ideia da retaliação coletiva levanta uma série de problemas, incluindo o estabelecimento de um sistema para garantir que as sanções aplicadas por todos os membros não excedam a quantidade autorizada. Além disso, desvios de comércio poderiam ocorrer, caso um país, apesar de suas obrigações, se recusasse a retaliar. Direto ao ponto, seria necessária uma alteração do ESC, a fim de se implementar o princípio da retaliação coletiva, e muitos países não concordariam em impor prejuízos

100 IERLEY, Douglas. Defining the factors that influence developing country compliance with and participation in the WTO dispute settlement system: another look at the dispute over bananas. Law and Policy in International Business, v. 33, p. 615652, 2002.

101 DILLON JUNIOR, Thomas J. The World Trade Organization: a new legal order for world trade? Michigan Journal of International Law, v. 16, n. 2, p. 349-402, 1995.

102 VAZQUEZ, Carlos M.; JACKSON, John H. Some reflections on compliance with WTO dispute settlement decisions. Law and Policy in International Business, v. 33, n. 4, p. 555568. 2002.

103 NGANGJOH, Yenkong; RIOS-HERRAN, Roberto. WTO dispute settlement system and the issue of compliance: multilateralizing the enforcement mechanism. Manchester Journal of International Economic Law, v. 1, n. 3, p. 15-30, 2004. 
comerciais às suas economias para resolver uma disputa comercial que não lhes diz respeito. ${ }^{104}$

De modo geral, há várias mudanças práticas que poderiam melhorar a implementação das decisões da OMC, particularmente: (i) substituição da suspensão das concessões por multas; (ii) retroatividade, de modo a encorajar a conformidade dentro do período de tempo razoável; e (iii) mecanismo de ajuste para aumentar o nível de sanções, ao longo do tempo, e evitar que o incumprimento torne-se uma opção viável. ${ }^{105}$

Primeiro, o possível remédio mais óbvio é permitir que uma parte escolha entre a suspensão das concessões e o recebimento de um pagamento monetário periódico. Todavia, como variam as capacidades financeiras dos membros da OMC, o sistema teria de ser ajustado a elas, a fim de ser efetivo tanto aos ricos quanto aos pobres. ${ }^{106}$ Assim, os prejuízos monetários poderiam induzir o cumprimento de forma mais eficaz do que a retaliação comercial, porque os governos teriam que arcar com os custos, em vez de simplesmente transferi-los. ${ }^{107}$

Segundo, a natureza prospectiva dos recursos da OMC não incentiva os países ao pronto cumprimento, ao contrário, encoraja a morosidade. Para minimizar esse problema, qualquer que seja o remédio (retaliação ou pagamento em dinheiro) deve ser calculado a partir de uma data anterior à prevista para implementação (por exemplo, data de aprovação do relatório em causa ou data de constituição do painel ou mesmo antes), assim, afastando a regra atual que possibilita o incumprimento dentro do período de tempo razoável. ${ }^{108}$ Conquanto um processo rápido não possa ser substituído pela aplicação retroativa dos custos aos infratores, esta ajuda a diminuir os danos causados ${ }^{109}$.

104 MCGIVERN, Brendan P. Seeking compliance with WTO rulings: theory, practice and alternatives. International Lawyer $(A B A)$, v. 36, n. 1, p. 141-158, 2002.

105 DAVEY, William J. Compliance problems in WTO dispute settlement. Cornell International Law Journal, v. 42, n. 1, p. 119-128, 2009.

106 DAVEY, William J. Compliance problems in WTO dispute settlement. Cornell International Law Journal, v. 42, n. 1, p. 119-128, 2009

107 CHARNOVITZ, Steve. Rethinking WTO trade sanctions. American Journal of International Law, v. 95, n. 4, p. 792- 832, 2001.

108 DAVEY, William J. Compliance problems in WTO dispute settlement. Cornell International Law Journal, v. 42, n. 1, p. 119-128, 2009 .

109 NGANGJOH, Yenkong; RIOS-HERRAN, Roberto. WTO dispute settlement system and the issue of compliance:
Terceiro, o aumento das sanções ao longo do tempo ajudaria a evitar a percepção de que o pagamento de multas ou danos é simplesmente uma alternativa para o cumprimento. Em certo sentido, a Comunidade Europeia utilizou este conceito no caso do FSC quando impôs um imposto sobre uma longa lista de produtos dos EUA que começou em $5 \%$ e foi aumentado em $1 \%$ ao mês. O reajuste, ainda que mensalmente pequeno, elevou a sanções do FSC para a ordem de 4 bilhões de dólares, criando um incentivo para a mudança de comportamento. Dessa forma, o mesmo conceito poderia ser usado em outros casos para incentivar uma implementação mais rápida. Por outro lado, sanções crescentes ao longo do tempo aumentariam o custo da não conformidade, pois aumentariam a oposição política à implementação. Disputas da OMC são demasiado complexas, de modo que algumas medidas poderiam ser vistas pelos membros como uma forma mais drástica e menos aceitável de mudança, produzindo efeitos contrários aos pretendidos, por exemplo, paralisando o comércio. ${ }^{110}$

Ademais, outros expedientes podem ser alinhavados: (i) arbitragem, diante das dificuldades em se modificar as legislações domésticas, como um meio mais rápido e menos caro de se resolverem os conflitos comerciais internacionais; (ii) permissão de levarem novos casos à OMC apenas aos países que cumpriram integralmente as decisões; (iii) participação de terceiras partes no processo de disputa; (iv) compensação, como o melhor remédio, tanto em si mesmo, quanto como uma possível resposta ao descumprimento por parte dos países desenvolvidos. ${ }^{111}$

A sugestão mais promissora no sentido de facilitar a compensação envolve o estabelecimento de um procedimento para definir o nível de prejuízo, conferindo uma base mais clara para a realização de negociações de compensação, dentro de um tempo determinado. Contudo, a parte transgressora ainda teria que concordar com a compensação. Consequentemente,

multilateralizing the enforcement mechanism. Manchester Journal of International Economic Law, v. 1, n. 3, p. 15-30, 2004.

110 DAVEY, William J. Compliance problems in WTO dispute settlement. Cornell International Law Journal, v. 42, n. 1, p. 119-128, 2009.

111 IERLEY, Douglas. Defining the factors that influence developing country compliance with and participation in the WTO dispute settlement system: another look at the dispute over bananas. Law and Policy in International Business, v. 33, p. 615652, 2002 . 
ideias de compensação "obrigatória” são difíceis de serem implementadas quando o demandado é recalcitrante. ${ }^{112}$ Por outro lado, conquanto a compensação esteja sempre sujeita à concordância da parte infratora, a longo prazo, é vantajosa não só para as partes envolvidas, mas também para todos os membros da OMC. Por isso, por que não tornar a compensação obrigatória e automática como as contramedidas atualmente o são? Sem a necessidade de aprovação de ambas as partes, o OSC poderia, então, aprovar um pedido de compensação - sob a forma de, por exemplo, menor tarifa de importação, maior quota de importação ou acesso ao mercado ${ }^{113}$ - a ser concedido à parte prejudicada. Em caso de litígio sobre o montante da indenização pedida, a arbitragem obrigatória disponível para contramedidas poderia ser utilizada. Além disso, o atual regime de contramedidas, que visa induzir o cumprimento em vez de compensá-lo, poderia ser mantido. ${ }^{114}$ Expandir o uso da compensação seria particularmente desejável para os países em desenvolvimento que se encontram em uma situação em que a implementação não vai ocorrer e a ação de retaliação não é uma possibilidade prática, como é normalmente o caso. Mesmo que isso equivalha aos países ricos "comprarem" suas obrigações, no cômputo geral, seria um requisito útil. ${ }^{115}$ Apesar de amplamente aceita como preferível à retaliação, a compensação tem sido pouco utilizada, e quando utilizada, suas negociações têm sido sem sucesso. Isso porque as partes podem ter ideias muito diferentes sobre o que constitui uma adequada compensação. A solução pode vir de um precedente interessante e construtivo: no caso Lei de Direitos Autorais, EUA e CE realizaram uma arbitragem especial sobre o nível de perdas e danos

112 DAVEY, William J. Compliance problems in WTO dispute settlement. Cornell International Law Journal, v. 42, n. 1, p. 119-128, 2009 .

113 Na compensação sob a forma de maior acesso ao mercado, a parte demandada poderia, por exemplo, concordar em reduzir tarifas de produtos específicos enquanto se aguarda a retirada da medida ilegal. Fa-lo-ia com base no princípio da nação mais favorecida, o que teria a vantagem de expandir o comércio, ao invés de restringi-lo por meio de sanções MCGIVERN, Brendan P. Seeking compliance with WTO rulings: theory, practice and alternatives. International Lawyer $(A B A)$, v. 36, n. 1, p. 141-158, 2002.

114 PAUWELYN, Joost H. Enforcement and countermeasures in the WTO: rules are rules - toward a more collective approach. American Journal of International Law, v. 94, p. 335-347, 2000.

115 DAVEY, William J. Compliance problems in WTO dispute settlement. Cornell International Law Journal, v. 42, n. 1, p. 119-128, 2009. durante o período de implementação, o que facilitou a subsequente negociação de um acordo de compensação temporária entre as partes. ${ }^{116}$

De maneira específica, é possível, ainda, melhorar a capacidade técnica dos países em desenvolvimento, a partir de vários cenários: o estabelecimento de um corpo de voluntários jurídicos internacionais responsáveis pela formação de pessoal; a formação de funcionários de comércio internacional em vinte países por ano, por iniciativa da OMC; o oferecimento de sessões interativas na OMC; o oferecimento de cursos profissionalizantes nas universidades dos países desenvolvidos como parte dos pacotes de ajuda externa; e o estabelecimento pela Secretaria da OMC de centros regionais de suporte contínuo aos países em desenvolvimento. Todavia, entre essas iniciativas, afasta-se a ideia de se utilizarem escritórios particulares de advocacia, em virtude de seus custos, seus interesses em prolongar as disputas para obterem mais honorários e, principalmente, por não capacitarem os funcionários dos países em desenvolvimento, gerando um ciclo de dependência. ${ }^{117}$ Enfim, apoiar centros de assistência jurídica independente é, tanto por razões políticas quanto jurídicas, a única maneira das nações desenvolvidas honrarem suas obrigações autoimpostas de auxílio aos regimes de comércio das nações em desenvolvimento. ${ }^{118}$

Antes e acima de tudo, questões relacionadas ao cumprimento devem ser examinadas numa perspectiva mais ampla, que transcenda a análise estritamente legalista do regime de comércio e considere os interesses multifacetados $\mathrm{e}$ as diferenças entre os membros da OMC, sob pena de uma eventual reforma do sistema torná-lo demasiadamente rígido e inflexível, o que empurraria seus membros mais poderosos para o bilateralismo puro e simples. ${ }^{119}$

116 MCGIVERN, Brendan P. Seeking compliance with WTO rulings: theory, practice and alternatives. International Lawyer $(A B A)$, v. 36, n. 1, p. 141-158, 2002.

117 IERLEY, Douglas. Defining the factors that influence developing country compliance with and participation in the WTO dispute settlement system: another look at the dispute over bananas. Law and Policy in International Business, v. 33, p. 615652, 2002.

118 MCBRIDE, Thaddeus. Rejuvenating the WTO: Why the U.S. must assist developing countries in trade disputes. International Legal Perspectives, v. 11, n. 1, p. 6-102, 1999.

119 COLARES, Juscelino F. Thelimits of WTO adjudication: is compliance the problem? Journal of International Economic Law, v. 14 , n. 2, p. 403-436, 2011. 


\section{Considerações Finais}

A questão do cumprimento efetivo das regras e das decisões do sistema de solução de controvérsias da OMC tem estado, nos últimos anos, no centro das atenções acadêmicas. Por um lado, uma decisão construída juridicamente sob os auspícios de uma instituição internacional é, de forma evidente, mais bem aceita do que outra imposta pela força. Por outro, recorrer ao OSC não implica o cumprimento automático de suas decisões, pois o sistema é carente de mecanismos coercitivos eficazes, ou seja, imunes aos cálculos políticos de seus membros. Diante disso, a questão da conformidade é tão contestada que serve, a um só tempo, tanto aos defensores do regime jurídico da OMC, quanto aos seus detratores. O mesmo raciocínio aplica-se à questão do cumprimento perfeito, tantas vezes tomado como se fosse a quintessência. $\mathrm{O}$ fato de que os membros não tenham buscado sanções mais duras, quando da construção da OMC, não significa anuência a um mero cumprimento arbitrário. Por exemplo, a flexibilidade dos mecanismos de execução do regime jurídico da OMC funciona como uma importante válvula de segurança sistêmica. Portanto, esses problemas somente podem ser adequadamente compreendidos na intersecção entre as esferas jurídica e política.

O escopo principal de se constituir a OMC como um sistema baseado no direito foi o de diminuir o descumprimento das regras e decisões concernentes ao comércio internacional, ou mesmo a morosidade em cumpri-las. Contudo, por vezes, alguns membros utilizam o sistema como forma de adiar o cumprimento de uma decisão do painel ou do órgão de apelação: é a não conformidade materializada em morosidade. Além disso, é preocupante que a comunidade internacional comece a ver a organização como uma ferramenta incapaz de resolver equitativamente as disputas comerciais internacionais. A não ser que todas as partes num litígio sejam bem representadas, é improvável que resultados justos e eficazes sejam atingidos. Instrumentos jurídicos, a exemplo das sanções, são, no mínimo, contrários aos interesses comerciais de seus membros e à própria natureza da instituição internacional. Especificamente para as economias fracas, o recurso à retaliação não constitui sequer uma opção prática.

Diante disso, aventam-se algumas propostas para se aperfeiçoar um complexo sistema de solução de controvérsias. De modo geral, a título de exemplo, ressaltamos: (i) contramedidas comerciais coletivas, (ii) substituição da suspensão das concessões por multas; (iii) retroatividade das decisões; (iv) mecanismo de ajuste do nível de sanções, ao longo do tempo; (v) arbitragem; (vi) impedimento da apresentação de novos casos aos países que não cumpriram integralmente decisões anteriores; (vii) participação de terceiras partes no processo de disputa; (viii) compensação. De maneira específica aos países em desenvolvimento, destacamos, por exemplo: (i) estabelecimento de um corpo de voluntários jurídicos internacionais responsáveis pela formação de pessoal; (ii) formação de funcionários de comércio internacional em vinte países por ano, por iniciativa da OMC; (iii) oferecimento de sessões interativas na OMC; (iv) oferecimento de cursos profissionalizantes nas universidades dos países desenvolvidos como parte dos pacotes de ajuda externa; (v) estabelecimento pela Secretaria da OMC de centros regionais de suporte contínuo aos países em desenvolvimento.

Todavia, é preciso questionar se essas propostas seriam adequadas e se funcionariam em termos práticos, ou seja, se os países ricos aceitariam a substituição de remédios jurídicos que concedem aos países pobres direitos que eles não podem exercitar por outros verdadeiramente efetivos. Se as nações poderosas considerarão seus interesses de longo prazo e abdicarão de suas capacidades de se desviarem de suas obrigações internacionais, será talvez a questão mais importante para se determinar o quanto a OMC pode se aproximar de um sistema verdadeiramente jurídico, caracterizado pelo cumprimento de suas regras e decisões. 


\section{Referências}

BRIMEYER, Benjamin L. Bananas, beef, and compliance in the world trade organization: the inability of the WTO dispute settlement process to achieve compliance from superpower nations. Minnesota Journal of Global Trade, v. 10, p. 133- 168, 2001.

CHARNOVITZ, Steve. Rethinking WTO trade sanctions. American Journal of International Law, v. 95, n. 4, p. 792- 832, 2001.

DAVEY, William J. Compliance problems in WTO dispute settlement. Cornell International Law Journal, v. 42, n. 1, p. 119-128, 2009.

COLARES, Juscelino F. Thelimits of WTO adjudication: is compliance the problem? Journal of International Economic Law, v. 14, n. 2, p. 403-436, 2011.

DILLON JUNIOR, Thomas J. The World Trade Organization: a new legal order for world trade? Michigan Journal of International Law, v. 16, n. 2, p. 349402, 1995.

GINSBURG, Tom; MCADAMS, Richard H. Adjudicating in anarchy: an expressive theory of international dispute resolution. William and Mary Law Review, v. 45, n. 4, p. 1229-1340, 2004.

HORLICK, Gary. Dispute resolution mechanism: will the United States play by the rules? Journal of World Trade, v. 29, n. 2, p. 163-172, 1995.

HORLICK, Gary. WTO dispute settlement and the Dole commission.Journal of World Trade, v. 29, n. 6, p. 45-48, 1995.

HORLICK, Gary; COLEMAN, Judith. The compliance problems of the WTO. Arizona Journal of International and Comparative Law, v. 24, n. 1, p. 141-148, 2007.

HUDEC, Robert E. Broadening the scope of remedies in WTO dispute settlement. In: WEISS, Friedl (Coord.). Improving WTO dispute settlement procedures: issues and lessons from the practice of other international courts and tribunals. London: Cameron May, 2000. p. 345-376.

HUDEC, Robert E. Enforcing international trade law: the evolution of the modern GATT legal system. Salem, N. H.: Butterworth Legal Publishers, 1993.
HUDEC, Robert E. The GATT legal system and world trade diplomacy. 2. ed. New York: Praeger Publishers, 1990.

HUDEC, Robert E. The new WTO dispute settlement procedure: an overview of the first three years. Minnesota Journal of Global Trade, v. 8, n. 1, p. 01-54, 1999.

IERLEY, Douglas. Defining the factors that influence developing country compliance with and participation in the WTO dispute settlement system: another look at the dispute over bananas. Law and Policy in International Business, v. 33, p. 615-652, 2002.

JACKSON, John H. The WTO dispute settlement understanding: misunderstandings on the nature of legal obligation. The American Journal of International Law, v. 91, n. 1, p. 60-64, 1997.

JOERGENS, Konstantin J. True appellate procedure or only a two-stage process? A view of the appellate body under the WTO dispute settlement understanding. Law and Policy in International Business, v. 30, n. 2, p. 193 $-230.1999$.

KHANSARI, AzarM. Searching for the perfect solution: international dispute resolution and the new world trade organization. Hastings International and Comparative Law Review, v. 20, n. 1, p. 183-206, 1996.

MAVROIDIS, Petros C. Remedies in the WTO legal system: between a rock and a hard place. European Journal of International Law, v. 11, n. 4, p. 763-814, 2000.

MCBRIDE, Thaddeus. Rejuvenating the WTO: Why the U.S. must assist developing countries in trade disputes. International Legal Perspectives, v. 11, n. 1, p. 6-102, 1999.

MCGIVERN, Brendan P. Seeking compliance with WTO rulings: theory, practice and alternatives. International Lawyer (ABA), v. 36, n. 1, p. 141-158, 2002.

MORA, Miquel Montana I. A GATT with teeth: law wins over politics in the resolution of international trade disputes. Columbia Journal of Transnational Law, v. 31, n. 1, p. 103- 180, 1993.

NGANGJOH, Yenkong; RIOS-HERRAN, Roberto. WTO dispute settlement system and the issue of compliance: multilateralizing the enforcement 
mechanism. Manchester Journal of International Economic Law, v. 1, n. 3, p. 15-30, 2004.

PAUWELYN, Joost H. Enforcement and countermeasures in the WTO: rules are rules - toward a more collective approach. American Journal of International Law, v. 94, p. 335-347, 2000.

PRINCEN, Sebastiaan. EC compliance with WTO law: the interplay of law and politics. European Journal of International Law, v. 15, n. 3, p. 555-574, 2004.

SCHAEFER, Matthew. National review of WTO dispute settlement reports: in the name of sovereignty or enhanced WTO rule compliance? St. John's Journal of Legal Commentary, v. 11, n. 2, p. 307-350, 1996.

SULLIVAN, Helena D. Regional Jet Trade Wars: Politics and Compliance in WTO Dispute Resolution. Minnesota Journal of Global Trade, v. 12, p. 71-108, 2003.
TRACHTMAN, Joel P. Bananas, direct effect and compliance. European Journal of International Law, v. 10, n. 4, p. 655- 678, 1999.

VARELLA, M. D. Efetividade do Órgão de Solução de Controvérsias da Organização Mundial do Comércio: uma análise sobre os seus doze primeiros anos de existência e das propostas para seu aperfeiçoamento. Revista Brasileira de Politica Internacional, v. 52, n. 2, p. 0521, 2009.

VAZQUEZ, Carlos M.; JACKSON, John H. Some reflections on compliance with WTO dispute settlement decisions. Law and Policy in International Business, v. 33, n. 4, p. 555-568. 2002.

ZIMMERMAN, Claus D. Toleration of temporary non-compliance: the systemic safety valve of WTO dispute settlement revisited. Trade, Law and Development, v. 3, n. 2, p. 382-406, 2011. 
Para publicar na Revista de Direito Internacional, acesse o endereço eletrônico www.rdi.uniceub.br ou www.brazilianjournal.org.

Observe as normas de publicação, para facilitar e agilizar o trabalho de edição. 